OPEN ACCESS

Edited by:

Weihua Li,

University of Wollongong, Australia

Reviewed by:

Martin Stelzle,

University of Tübingen, Germany

Pinar Yilgor Huri,

Ankara University, Turkey

*Correspondence:

Stephanie M. Willerth willerth@uvic.ca

Specialty section:

This article was submitted to Biomaterials,

a section of the journal

Frontiers in Materials

Received: 19 November 2020 Accepted: 01 March 2021

Published: 22 March 2021

Citation:

Lawko N, Plaskasovitis C, Stokes C, Abelseth L, Fraser I, Sharma R, Kirsch R, Hasan M, Abelseth E and Willerth SM (2021) 3D Tissue Models

as an Effective Tool for Studying Viruses and Vaccine Development.

Front. Mater. 8:631373.

doi: 10.3389/fmats.2021.631373

\section{D Tissue Models as an Effective Tool for Studying Viruses and Vaccine Development}

\author{
Nathan Lawko 1,2, Charlie Plaskasovitis ${ }^{1,2}$, Carling Stokes ${ }^{2,3}$, Laila Abelseth ${ }^{2}$, lan Fraser ${ }^{3}$, \\ Ruchi Sharma ${ }^{3}$, Rebecca Kirsch ${ }^{4}$, Misha Hasan ${ }^{5}$, Emily Abelseth ${ }^{3}$ and \\ Stephanie M. Willerth ${ }^{2,3,5,6 *}$
}

${ }^{1}$ Department of Electrical and Computer Engineering, University of Victoria, Victoria, BC, Canada, ${ }^{2}$ Centre for Biomedical Research, University of Victoria, Victoria, BC, Canada, ${ }^{3}$ Department of Mechanical Engineering, University of Victoria, Victoria, BC, Canada, ${ }^{4}$ Department of Chemistry, University of Victoria, Victoria, BC, Canada, ${ }^{5}$ Biomedical Engineering Program, University of Victoria, Victoria, BC, Canada, ${ }^{6}$ Division of Medical Sciences, University of Victoria, Victoria, BC, Canada

The recent SARS-CoV-2 outbreak has researchers working tirelessly to understand the virus' pathogenesis and develop an effective vaccine. The urgent need for rapid development and deployment of such a vaccine has illustrated the limitations of current practices, and it has highlighted the need for alternative models for early screening of such technologies. Traditional 2D cell culture does not accurately capture the effects of a physiologically relevant environment as they fail to promote appropriate cell-cell and cell-environment interactions. This inability to capture the intricacies of the in vivo microenvironment prevents 2D cell cultures from demonstrating the necessary properties of native tissues required for the standard infection mechanisms of the virus, thus contributing the high failure rate of drug discovery and vaccine development. 3D cell culture models can bridge the gap between conventional cell culture and in vivo models. Methods such as 3D bioprinting, spheroids, organoids, organ-on-chip platform, and rotating wall vessel bioreactors offer ways to produce physiologically relevant models by mimicking in vivo microarchitecture, chemical gradients, cell-cell interactions and cell-environment interactions. The field of viral biology currently uses 3D cell culture models to understand the interactions between viruses and host cells, which is crucial knowledge for vaccine development. In this review, we discuss how 3D cell culture models have been used to investigate disease pathologies for coronaviruses and other viruses such as Zika Virus, Hepatitis, and Influenza, and how they may apply to drug discovery and vaccine development.

Keywords: COVID-19, biomaterials, tissue engineering, organoids, antigen, microenvironment

\section{INTRODUCTION}

Viruses, infectious agents, can only replicate in a host organism (Lodish et al., 2000). Prior to infection of a host, viruses exist as independent particles called virions. Virions contain nucleic acids, most commonly DNA or RNA, that allow them to mutate and evolve. A coat consisting of proteins or lipids called a capsid protects their genetic material. Viral infection occurs when proteins on the surface of a virion bind to specific receptor proteins on the surface of host cells. After infection, a virus will hijack the machinery of the host cell to produce and release copies of 
the virus to infect nearby cells. If a person has not encountered this virus before, their immune system undergoes a process to identify these viral particles as being foreign and then remove them from the body. The immune system then retains memory of that virus. A vaccine is a biological agent that elicits a protective immune response targeting a particular pathogen without requiring the host to acquire the disease (Vetter et al., 2018). There are several types of vaccines, each with different ways of inducing different adaptive immune mechanisms. Liveattenuated vaccines are composed of pathogens that have been adapted to be less virulent than the functional virus. Healthy vaccine recipients develop long-term immunity similar to having recovered from the viral infection (Vetter et al., 2018). Inactivated vaccines use deactivated pathogens that are incapable of causing infection. While inactivation destroys the ability of the virus to replicate, its immunogenicity is retained to allow the immune system to target the pathogen. Subunit and conjugate vaccines use select fragments of a pathogen, such as proteins, polysaccharides, or parts of a virus that may form viruslike particles, to incite an immune response. Toxoid vaccines utilize inactivated toxins that, while no longer harmful, preserve their ability to induce toxin-neutralizing antibodies (Vetter et al., 2018). Modern vaccine designs have been introduced to address limitations of current vaccine types. These technologies include nucleic-acid based vaccines that insert DNA or RNA encoded with antigenic proteins into cells, and recombinant vector vaccines use non-pathogenic vectors, such as a virus or bacterium, to introduce the foreign genetic material into cells (Vetter et al., 2018; NIAID, 2020).

A potential vaccine must be assessed for toxicity, induced immunogenic response, efficacy, and impact on public health while meeting guidelines of regulatory health agencies before being approved for use in humans (Singh and Mehta, 2016). The development process can be divided into the preclinical stages (in vitro and in vivo animal tests) followed by the three clinical stages using human subjects. Only a select few vaccines currently in development will successfully complete the transition from laboratory to clinical trials. The development timeline of vaccines can take anywhere from 5 years at an accelerated rate to upwards of 15 years (Bregu et al., 2011). It was found that only $16.2 \%$ of vaccines were able to advance from preclinical trials to Food and Drug Administration approval in the United States from 2006 to 2015 (Thomas et al., 2016). The associated cost of vaccine development from discovery to licensure can come to billions of dollars (Gouglas et al., 2018). With over 100 million people and counting diagnosed worldwide, the COVID-19 pandemic has catalyzed an international effort to produce a vaccine aiming to provide immunity against the severe acute respiratory syndrome coronavirus 2 (SARS-CoV-2) virus, resulting in some promising results.

SARS-CoV-2 has affected millions of people globally, resulting in a shift of research toward drug and vaccine development (Draft Landscape of COVID-19 Candidate Vaccines, 2020). On January 11th, 2020 the genetic sequence of the novel coronavirus was identified, catalyzing the search for a suitable vaccine against the virus (Thanh Le et al., 2020). There are currently
66 candidate vaccines against SARS-CoV-2 in clinical trials, and over 100 in preclinical evaluation (Draft Landscape and Tracker of COVID-19 Candidate Vaccines, 2021). The use of 2D cell culture can facilitate drug discovery and optimize the vaccine development process. The process of cell culture grows and maintains living cells in an artificial environment. Cell culture has proved useful in understanding the fundamental molecular and physical processes that allow cells to assemble into tissues and organs, how tissues to function, and how tissues respond to diseases and treatment with drugs (Duval et al., 2017; Kapałczyńska et al., 2018). Life science research often uses mammalian cell culture as a tool for drug discovery, including manufacturing viral vaccines (Hu, 2020; Ryan, 2020). In comparison to traditional $2 \mathrm{D}$ cell culture systems, threedimensional (3D) cell culture can serve as a better model system for vaccine development by providing a microenvironment that replicates the physiological setting of real cells, enabling better identification of toxicity and other unwanted issues earlier in drug development (Ravi et al., 2015). 2D cell cultures only partially exhibit the morphology and biochemical behavior necessary for viral infection while being unable to imitate the intricacies of microenvironment of in vivo (Rosellini et al., 2019). These limitations can be addressed by 3D cultures that create a tissue-specific microenvironment that mimics in vivo microarchitecture, oxygen, nutrient and metabolic waste gradients, cell-cell interactions and cell-extracellular matrix (ECM) interactions. 3D cell culture generates physiologically relevant models that can be used for drug discovery and highthroughput screening (Langhans, 2018), and can thus serve as an alternative technique for studying viral replication, bridging the differences between conventional cell culture and in vivo models (D'Aiuto et al., 2018; Rosellini et al., 2019). A comparison of studies between $2 \mathrm{D}$ cell monolayers and 3D cellular aggregates showed that the latter were better predictors of drug responses in vivo (He et al., 2016). Such preclinical models can more accurately predict clinical outcomes, saving both time and cost during the vaccine development process (Peng et al., 2017; Zhu and Ding, 2017; Cairns et al., 2020; Takayama, 2020). Thus, the substitution of $2 \mathrm{D}$ cultures by $3 \mathrm{D}$ cultures in drug screening requires swift, robust technologies amenable to analysis in a reliable manner (Zhu and Ding, 2017; Bhowmick et al., 2018; Cairns et al., 2020). 3D tissue models can provide insight and understanding into the complex interactions between viruses and their host cells that can be useful in the vaccine development process. 2D and 3D cell culture images are shown in Figure 1 to illustrate the differences between these culture methods. This review will discuss the progress made in the field of viral biology using 3D cell culture methods on various viral infections, such as Zika Virus, Hepatitis, Influenza, and Coronaviruses, as well as outline its potential for the development of viral vaccines with a particular focus on SARS-CoV-2.

\section{D Cell Culture}

3D cell culture can be accomplished by using either a scaffold, cell supporting matrix, or non-scaffold-based culture method (Costa et al., 2016). A variety of 3D culture methods have been used 


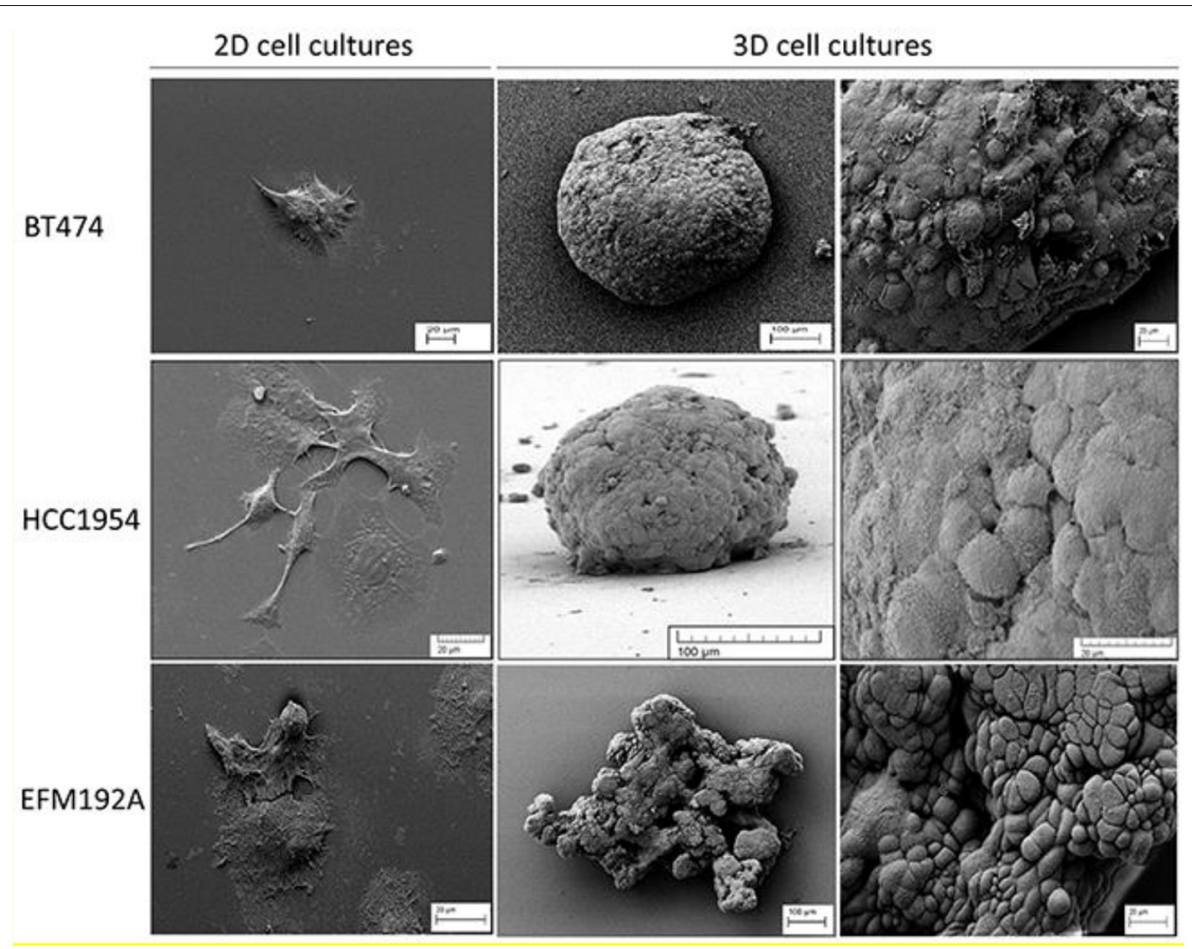

FIGURE 1 | SEM (scanning electron microscope) images of 2D and 3D cell cultures that illustrate the difference in cell morphology for three different breast cancer lines. Both BT474 and HCC1954 cells form tightly packed spheroids when grown in 3D, while EFM192A cells form a less organized 3D structure under the same conditions. Scale bars are shown on the images. This figure is reprinted under the terms of the Creative Commons Attribution License from Breslin and O'Driscoll (2016).

to study viral biology, such as 3D hydrogels, 3D bioprinting, spheroids, organoids, rotating wall vessel (RWV) bioreactors, and organ-on-a-chip (OOAC) platforms (Figure 2). Hydrogels are 3D networks composed of hydrophilic polymer chains that retain their structure due to crosslinking of individual polymer chains (Bahram et al., 2016). With a wide range of natural and synthetic hydrogels, the versatility of hydrogels makes them suitable for designing scaffolds with predefined physiological and mechanical properties that effectively mimic the extracellular matrix, making them useful in the field of tissue engineering and drug discovery (Tibbitt and Anseth, 2009; Ruedinger et al., 2015).

$3 \mathrm{D}$ bioprinting is the additive manufacturing of biological structures that allows for the precise recreation of complex tissue microenvironment. The high resolution obtained by $3 \mathrm{D}$ bioprinting is due to the layer-by-layer positioning of biological materials, biochemicals and living cells to fabricate tissues structures (Murphy and Atala, 2014; Ozbolat, 2015). Consequently, 3D bioprinting techniques, with their capability to automate the creation of $3 \mathrm{D}$ tissue structures, stands out amongst the different methods for producing biomimetic tissue (Berg et al., 2018; de la Vega et al., 2019). 3D bioprinted models can overcome most of the drawbacks in a $2 \mathrm{D}$ in vitro cell model. For instance, in a $2 \mathrm{D}$ model where the growth substrate is attached to a hard-plastic surface, cells can lose their characteristics due to limited cell-cell or cellECM interaction. However, the 3D structural model allows the cell culture to grow in the same way as within the human body, maintaining single-cell characteristics and analogously replicating the complex structures and physiological functions. The reliability of results from using these tissues is far higher than that of the 2D cell culture models (Peng et al., 2017; Centeno et al., 2018).

Spheroids are micro-sized cellular aggregates that are widely used in the field of oncology (Ryu et al., 2019). They mimic the characteristics of solid tumors from various cancer types in vitro, making them highly suitable for in vitro oncological drug testing. Liquid overlay, hanging drop, microfluidic-based assembly, and spinner flasks can all be used to produce spheroids. Spheroids simulate the communication between cells and interactions between the cells and the ECM better than 2D cell models (Rosellini et al., 2019; Ryu et al., 2019). Cellular spheroids can overcome limitations related to conventional in vitro systems for viral isolation (Rosellini et al., 2019). The sensitivity and efficiency of isolation of three existing viral species, Adenovirus, CMV, and HSV-1, in 2D have been studied in spheroids composed of susceptible cells (Rosellini et al., 2019; Cairns et al., 2020). The results indicate that $3 \mathrm{D}$ culture systems allow for earlier and more sensitive virus isolation than in traditional $2 \mathrm{D}$ systems, proving the importance of $3 \mathrm{D}$ culture systems in the virologic field for the improvement and evolution of more efficient and accurate virus isolation protocols (He et al., 2016). Organoids, mini tissues modeling simplified versions of an 


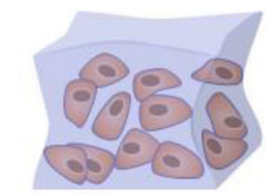

Cell-Containing Hydrogel

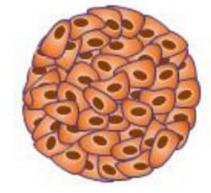

Spheroid

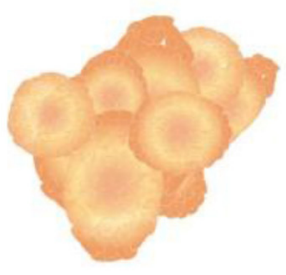

Organoid

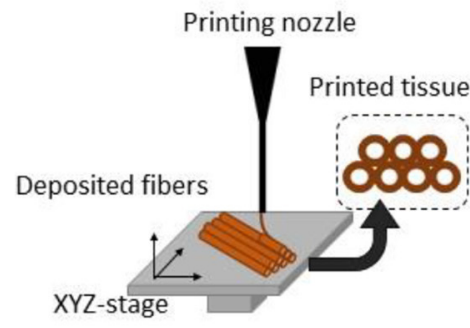

3D Bioprinting

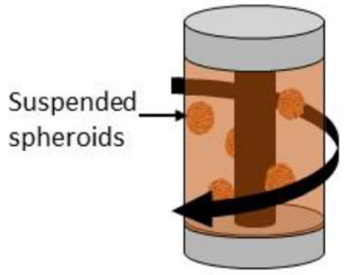

Rotating Wall Vessel Bioreactor (RWV)

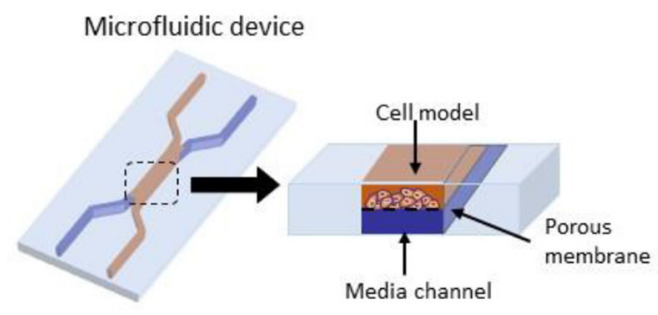

Organ-on-a-Chip (OOAC)

FIGURE 2 | Different methods of 3D cell culture, including 3D hydrogels, spheroids, organoids, 3D bioprinted tissues, organ-on-a-chip (OOAC), and rotating wall vessel (RWV) bioreactors.

organ that are produced in vitro, can replicate the properties of the target tissue. Derived from primary tissues or stem cells, organoids self-organize into a 3D structure due to their differentiation capacity (Yin et al., 2016). With their realistic microanatomy and physiological relevance, organoids have gained attention for their potential in developmental biology, disease pathology, cell biology, regenerative mechanisms, precision medicine, and drug toxicity and efficacy testing (Rossi et al., 2018).

Bioreactors are mechanical devices with the means to influence biological and/or biochemical processes (Plunkett and O'Brien, 2011). With the ability to closely monitor and enable controlled and reproducible changes of specific environmental factors, bioreactors are suitable for the in vitro development of tissue by providing regulatory biological, chemical, and physical cellular signals (Martin et al., 2004; Plunkett and O’Brien, 2011). Initially designed to model microgravity, National Aeronautics and Space Administration's (NASA's) RWV bioreactor has been found to provide an accurate physiological representation of human tissues in vivo. The low-shear environment promotes cell-cell interactions, a more homogenous cell distribution in comparison to $2 \mathrm{D}$ culture, the induction of differentiation, and the effects on intracellular signal transduction and gene expression due to the randomized gravitational vectors (Plunkett and O'Brien, 2011; Qian et al., 2016), thus allowing for the formation of complex 3D tissue-like aggregates. These aggregates express cellular architectural and structural features that are vital in analyzing virus-host interactions, such as tight junction proteins, mucus and microvilli, and thus can potentially be used to screen therapeutic agents and antiviral drugs in preclinical studies (Gardner and Herbst-Kralovetz, 2016).

While single-cell microfluidics have been instrumental in developing an understanding of the molecular and cellular basis of virus-host interactions, the platform does not allow for the study of cell-to-cell spread of a viral infection (Liu et al., 2020). Recently, microfluidic OOAC systems, such as liver and lung chips, have been used to reproduce viral infections such as Influenza and Hepatitis (Tang et al., 2020). OOAC is a biomimetic, microfluidic system that regulates concentration gradients, shear force, cell patterning, tissueboundaries, and tissue-organ interactions to simulate the physiological environment of an organ or organ system (Wu et al., 2020). OOACs have applications in preclinical drug testing and screening, as well as in drug discovery (Zhang et al., 2018). While there have been limited studies conducted using microfluidics for 3D viral culturing, the combination of a microfluidic OOAC platform and 3D cell culture can better mimic organ-specific responses and create more physiologically relevant models that can be applied to viral studies for vaccine development (Simpson et al., 2018; Tang et al., 2020). Each of the $3 \mathrm{D}$ cell culture techniques discussed can and has been employed in the study of various viruses, allowing more accurate modeling of viral behavior in an animal system. The following sections discuss applications of these techniques for specific viruses and models, and how they could be applied to the novel SARS-CoV-2 virus. 


\section{Coronaviruses}

The scientific and medical communities and vaccine industry are rapidly trying to develop a vaccine to address the recent outbreak of the novel coronavirus SARS-CoV-2. Previous experience with vaccines for H1N1 influenza have highlighted the need for novel design and manufacturing platforms (Tatara, 2020). Coronaviruses, or Orthocoronavirinae, are enveloped viruses with a single-stranded RNA genome. They are generally characterized by five major components: the envelope protein, membrane glycoprotein, spike protein, nucleocapsid protein and a single stranded RNA genome (Tatara, 2020). As a positive single-stranded virus, SARS-CoV-2 replicates in the cytoplasm and does not depend on RNA polymerase for transcription (Tatara, 2020). SARS-CoV-2 is thought to be spread primarily through aerosolized droplets due to coughing, sneezing and talking. The virus primarily affects the epithelial tissue of the lungs and causes acute respiratory distress syndrome in 5-10\% of infected individuals (Tatara, 2020). Given the severity of the morbidity and mortality rates associated with SARS-CoV2 , there is an urgent need for a deeper understanding of the viral mechanisms of the virus-host interactions of SARS-CoV2 , and more comprehensive and prompter screening of potential vaccines and other therapeutic strategies.

Although animal models have been instrumental in studying disease and the human lung, given the physiological differences between human and animal lungs, it is unsurprising that animal models cannot effectively model the complete pathophysiology of the human lung. Up to $80 \%$ of drug therapies that pass preclinical animal trials fail to treat human diseases during clinical trials (Miller and Spence, 2017). One way to better characterize the host-virus interactions and infection mechanisms and screen therapeutics is with the use of in vitro modeling with human cells. In vitro modeling of viral diseases can assist in identifying and profiling biomarkers and understanding host-virus interactions and mechanisms for transmission-two crucial pieces in the pursuit of hypothesis-based diagnostic and therapeutic objectives. Currently, in vitro antiviral modeling, specifically of Zika and Ebola virus, relies on a monolayer cell culture of Vero cells - kidney epithelial cells isolated from the African green monkey (Johansen et al., 2015; Adcock et al., 2017). These monocultures of Vero cells lack interferon, making them highly susceptible to viral infection and replication. However, interferon plays an important role in host binding for proteins involved in SARS-CoV-2 (Ziegler et al., 2020). Thus, it provides a major challenge when using these cell cultures to model the virus and screen potential therapies for SARSCoV-2. A drug's usefulness in inhibiting an infection in a primate kidney cell that does not produce interferon will not necessarily provide the appropriate and definitive therapeutic options needed for humans (Tatara, 2020). In general, these static xenograft animal cell cultures cannot always replicate the specific conditions and architectural features of human in vivo tissues that viruses encounter.

In the study of severe acute respiratory syndrome coronavirus (SARS-CoV-1), Suderman et al. engineered 3D tissue assemblies with a RWV bioreactor as a co-culture of human broncho-tracheal cell lines, with a mesenchymal component as the matrix and human broncho-epithelial cells (BEAS-2B) (Goodwin, 2006). Figure 3A shows the NASA designed RWV bioreactor used in the aforementioned study (Gardner and Herbst-Kralovetz, 2016) and 3B shows its different applications. Although no infectious virions were detected in the cell culture over the course of the infection, there was evidence of cross-reactivity between antibodies and viral spike and nuclear proteins in the SARS-CoV-1 infected tissue (Gardner and Herbst-Kralovetz, 2016). However, during the 10-day study of the tissue, cytoplasmic vacuolization, mitochondria loss, and endoplasmic reticula disturbance were also observed, indicating clear signs of infection. Although no virions were observed, these other host response mechanisms indicate a viral infection, suggesting that these cell cultures could provide important information about SARS-CoV-1 pathogenesis and infection. These initial experiments with $3 \mathrm{D}$ respiratory tissues could provide valuable information for new novel respiratory viruses, such as SARS-Cov-2 (Gardner and Herbst-Kralovetz, 2016).

In February of 2020, Monteil et al. isolated the SARS-CoV2 from a sample from patient in Sweden to study therapeutic options for COVID-19 (Monteil et al., 2020). The study investigated whether inhibiting the interaction of angiotensin converting enzyme 2 (ACE2), the key receptor for the spike glycoprotein of SARS-CoV-2, and SARS-CoV-2 may be a viable option for treating patients of COVID-19. The report concluded that clinical grade-human recombinant soluble ACE2 (hrsACE2) can reduce viral load in Vero cells by a factor of between 1,000 and 5,000. After culturing Vero E6 cells, the virus was sequenced using next-generation sequencing. It was determined that hrsACE2 both inhibits the attachment of the virus to the cells and that this inhibition is dose dependent. The primary infection site of COVID-19 is the lungs, which may be the source of the spread of infection to other tissues like the kidney and intestine (Monteil et al., 2020). The researcher hypothesized that to infect larger local tissues, capillaries must first be infected. Human capillary organoids were established from induced pluripotent stem cells (iPSCs) (Figure 4A) and infected with SARS-CoV-2. The experiment demonstrated that viral RNA could be detected in the blood vessel organoids and that the viral RNA increased from day 3 to day 6 , suggesting active replication of the virus (Figure 4B). A similar experiment was run on human kidney organoids. In both experiments, the infected organoids were then used to successfully infect Vero E6 cells, showing that the infected blood vessel and kidney organoids could produce infections in other tissues (Figure 4C). When hrsACE2 was added, infections in the human organoids were reduced in a dose-dependent way (Figure 4D). The data from this research shows that human engineered organoids can be infected with SARS-CoV-2, and during early stages, the infection can be inhibited significantly by hrsACE2 (Monteil et al., 2020). Thus, these engineered tissue models provide important insight in virus interactions.

Another useful resource in determining the pathophysiology of coronavirus infections and providing potential for drug screenings are the development of 3D in vitro human engineered lung tissue models. In recent years, primary human lung cells have been cultured into $3 \mathrm{D}$ tissue arrangements resembling multiple structures of the human lung. Although many of 

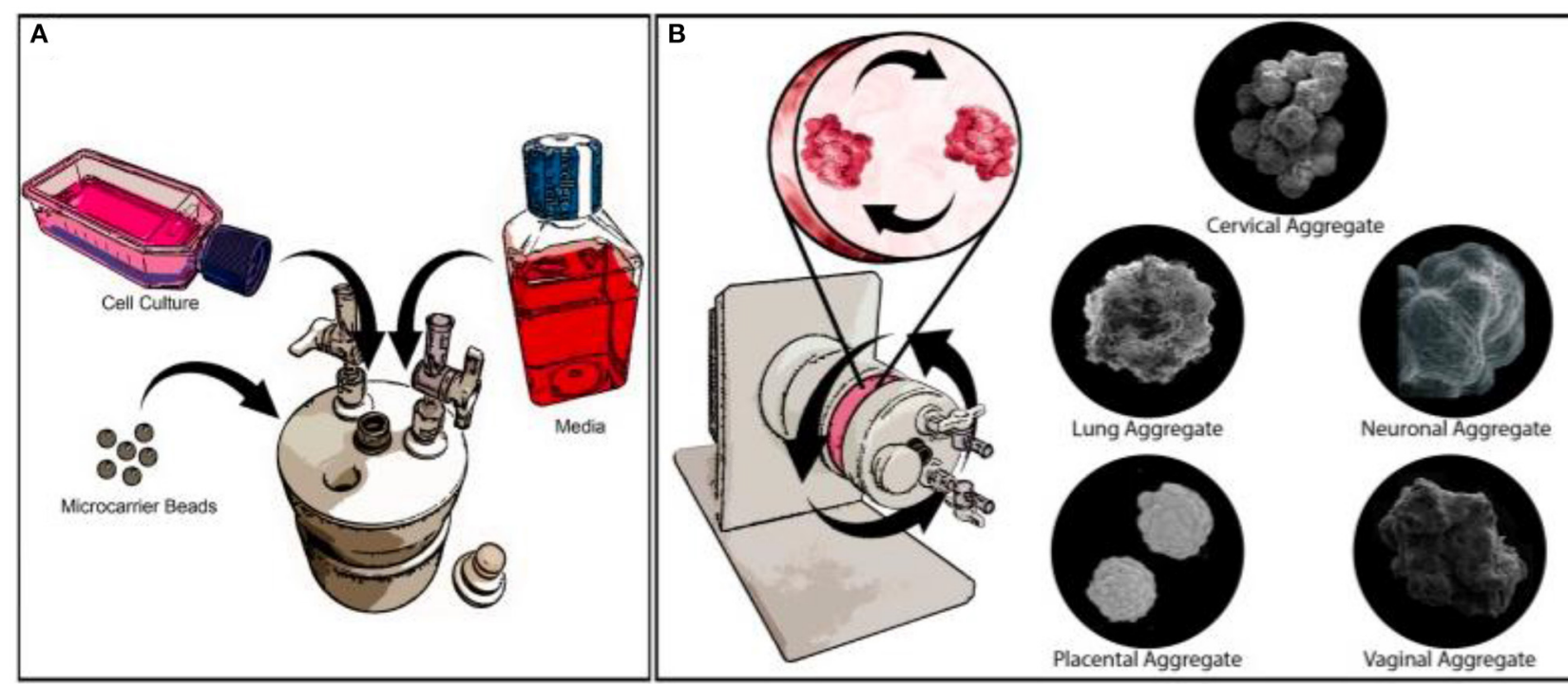

FIGURE 3 | The RWV bioreactor used to engineer 3D tissues for the co-culture of human broncho-tracheal cell lines and human broncho-epithelial cells. (A) Confluent cells grown in 2D are combined with media and microcarrier beads in the bioreactor (B) The RWV was used in other studies to form tissue aggregates. It is kept in continuous rotation to prevent detachment and accumulation of cells at the bottom of the bioreactor. This figure is reprinted under the terms of the Creative Commons Attribution License from Gardner and Herbst-Kralovetz (2016).

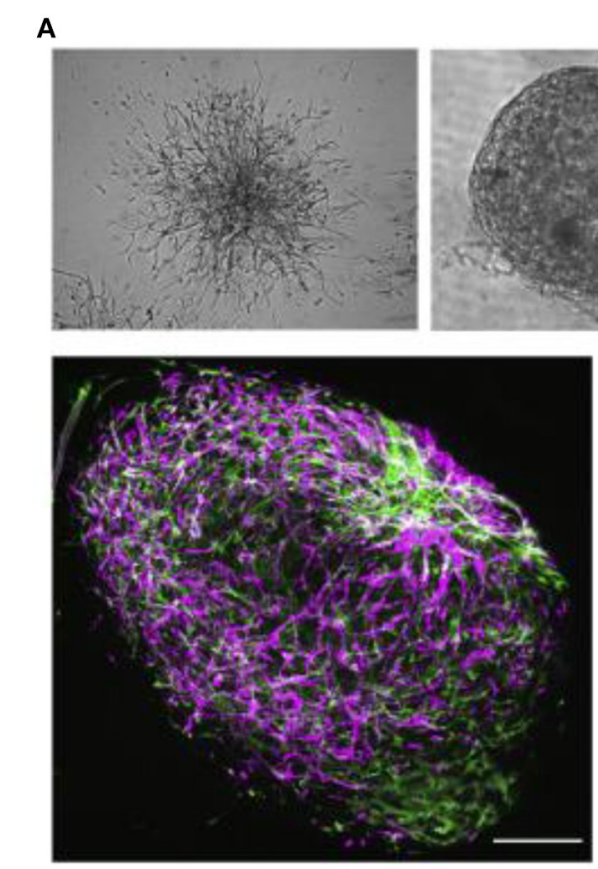

B

$10^{2}$ PFU
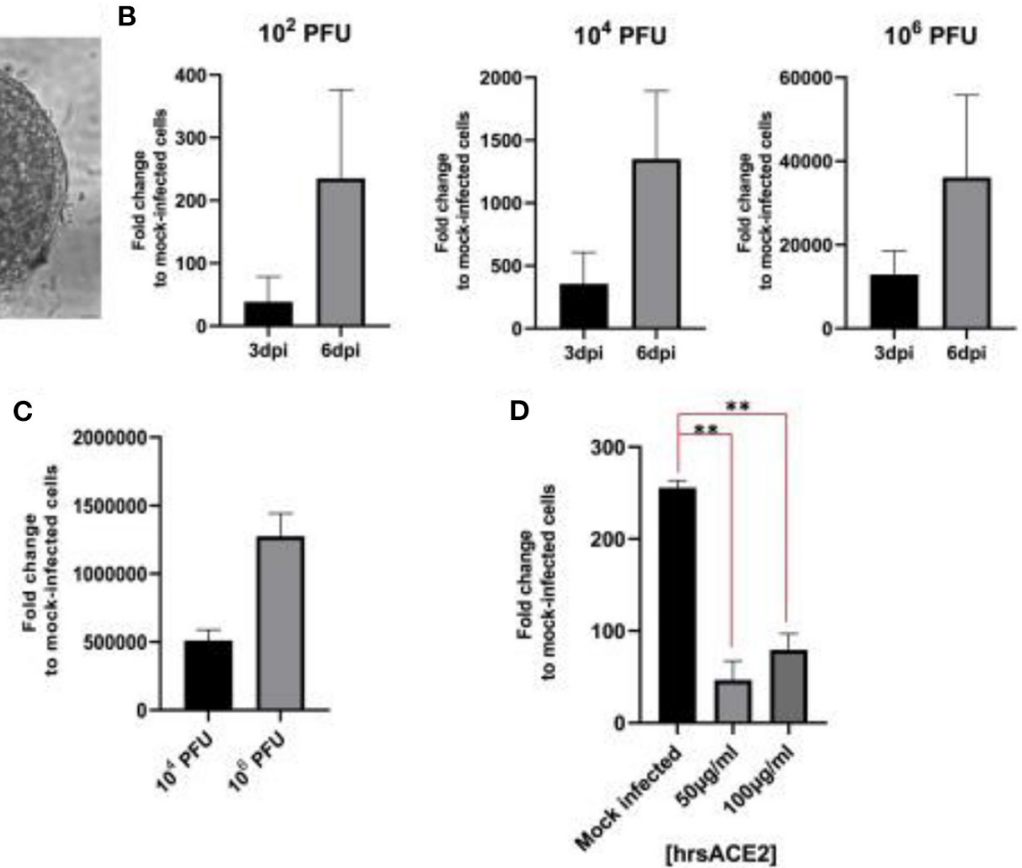

FIGURE 4 | (A) Vascular capillary organoids imaged using light microscopy (upper) and blood vessel organoids using imaged with immunostaining to detect endothelial cells and pericytes (lower). (B) Viral RNA recovered from organoids at day 3 and 6 after SARS-CoV-2 infection. (C) The supernatant from SARS-CoV-2 infected organoids 6 days after infection were used to infect Vero E6 cells. (D) Effect of hrsACE2 on vascular organoids infected with SARS-CoV-2 after organoids were infected with $10^{6}$ infectious particles and hrsACE2 for $1 \mathrm{~h} 3$ days after SARS-CoV-2 infection. Results were measured using qPCR. Scale bars are 500 and $50 \mathrm{~mm}$. This figure is reprinted under the terms of the Creative Commons Attribution License from Monteil et al. (2020). ${ }^{* *}$ indicates a significant difference between the conditions. 
these models have not been used to study coronaviruses directly, they provide insight into various tissue-engineered technologies can be leveraged to study respiratory viruses and viral infections. For example, a 3D environment of human "bronchospheres" has been developed from a population of primary human bronchiolar epithelial cells (Rock et al., 2009). This in vitro clonal sphere-forming assay isolated mouse basal stem cells and human epithelial tissue and embedded them into a 3D ECM gel (Rock et al., 2009). These experiments looked at cell behavior, primarily regeneration and differentiation, and found that the mouse basal stem cells were capable of self-renewal and generation of differentiated daughter cells. The assays developed in these experiments revealed potential mechanisms that regulate basal cells and allowed for comparison to other epithelial stem cells, they can also facilitate the study of the development, maintenance, and repair of epithelial airways and the mechanisms that regulate them (Rock et al., 2009). Bronchiolar epithelial cells have also been co-cultured with lung microvascular endothelial cells and lung fibroblasts in a $3 \mathrm{D}$ culture to create airway organoids (Tan et al., 2018). The study demonstrated that the randomly mixed cell populations underwent rapid self-organization and cell condensation into epithelial and endothelial structures. The structures remained stable and mechanically robust over the long-term culture. Interestingly, despite the proximal source of epithelium, both proximal and distal epithelial properties were observed, demonstrating the high-level plasticity of the organoid. The results demonstrated that the $3 \mathrm{D}$ airway organoid culture offers a new tool for the study of lung-based diseases and cell-based therapy (Tan et al., 2018). Biological scaffolds can also be used to generate $3 \mathrm{D}$ cell models. These consist of ECM from decellularized rodent and human lungs reseeded with human lung cells (Booth et al., 2012; Gilpin and Ott, 2015). Researchers have also bioengineered structural scaffolds to mimic the human lung environment (Miller and Spence, 2017). Many studies have succeeded in seeding primary murine lung cells onto natural ECM material, such Matrigel (Andrade et al., 2007) or collagen (Mondrinos et al., 2007), and synthetic materials, such as polylactic-co-glycolic acid (PGLA) and polyglycolic acid (PGA) (Cortiella et al., 2006). All of these approaches provide significant advantages over 2D monolayer cell cultures.

\section{Using 3D Culture Models to Study the Influenza A Virus}

Influenza is a major cause of death worldwide, claiming between 250,000 and 50,000 lives per year globally (Bhowmick et al., 2018). More specifically, the influenza A virus (IAV) is one of the leading causes of severe respiratory diseases worldwide (Berg et al., 2018). IAV infections are associated with high morbidity and mortality worldwide (Berg et al., 2018; Bhowmick et al., 2018). Influenza A, B, and C are characterized by negativestrand segmented RNA genomes then further categorized by the antigenicity of two surface glycoproteins, the hemagglutinin (HA) and neuraminidase (NA) subtypes (Bouvier and Palese, 2008; Bhowmick et al., 2018). Although there are many distinctive genetic subtypes, nine subtypes for NA and 16 subtypes for HA, only two NA (N1 and N2) and three HA $(\mathrm{H} 1, \mathrm{H} 2$, and $\mathrm{H} 3$ ) have led to widespread, epidemic-like personto-person transmission in humans (Bouvier and Palese, 2008). The H1N1 IAV strain that emerged in 2009 marked the first influenza pandemic of the 21st century, with over 61 million people falling ill in the United States alone (Bhowmick et al., 2018). Additionally, the CDC estimates that between 151,700 and 575,400 people died worldwide during the first year of $\mathrm{H} 1 \mathrm{~N} 1$ circulation (CDC, 2021). The segmented genome in the influenza virus supports antigenic shift, allowing influenza virus strains to obtain HA and NA segments from an influenza virus of different subtype. Step-wise mutations yield periodic changes in the amino acid substitutions in the RNA segments and therefore the antigenic characteristics of the HA and NA called antigenic drift (Radigan et al., 2015). When two viruses infect a single host, the antigenic shift of these segments can lead to the formation of novel strains of influenza that encode antigenic proteins to which immune systems are unable to fight (Bouvier and Palese, 2008; Radigan et al., 2015). Influenza viruses target human epithelial cells throughout both the upper and lower respiratory tracts (Radigan et al., 2015). Currently, there are several models available to study the immunopathology of IAV including animal models, ex vivo human tissue models, $2 \mathrm{D}$ cell culture models, and more recently, $3 \mathrm{D}$ cell culture models.

A study conducted in 2018 by Bhowmick et al. marked the first step in designing and creating a complete 3D-Human TissueEngineering Lung Model (3D-HTLM) (Bhowmick et al., 2018). The study described the $3 \mathrm{D}$ culture of primary human small airway epithelial cells (HSAEpCs) on a 3D chitosan-collagen scaffold (Figure 5C) to determine the immunophenotype of the IAV infection in response to two IAV strains, H1N1 and H3N2 (Figure 5A) (Bhowmick et al., 2018). When compared to $2 \mathrm{D}$ cultures of HSAEpCs (Figure 5B) in terms of viability, cell differentiation, morphology, and cell marker protein expression, the results confirmed that the $3 \mathrm{D}$ cultured HSAEpCs yielded a higher number of viable cells $(25.6 \%$ higher than in 2D cultures; Figure 5D), closely resembled and displayed characteristics of the in vivo airway epithelium in morphology and marker protein expression. When taken together, the results show that the $3 \mathrm{D}$ cultured HSAEpCs provide an adequate environment for 3DHTLM development (Bhowmick et al., 2018). This study takes the first step in developing a complete 3D-HTLM that could have broad applicability in the study of the pathology of respiratory diseases and the development of vaccines or other therapies.

Another study performed in 2018 by Berg et al. looked at how efficiently different 3D bioprinted cultures were infected by IAV and compared the results to a natural lung and a conventional 2D cell culture model (Berg et al., 2018). Researchers used optimized $3 \mathrm{D}$ printed cell-laden alginate, gelatin and Matrigel hydrogels (Figure 6) to print human alveolar epithelial (A549) cells into a spatially controlled model. The study drew comparisons between the $2 \mathrm{D}$ and $3 \mathrm{D}$ models, highlighting that $2 \mathrm{D}$ cultures adhere to a flat surface, limiting the physiological condition of the cells. Additionally, they noted that infection of a homogenous 2D culture is unlike an IAV infection in the human respiratory tract because in the respiratory tract, not all alveolar cells are homogeneously affected by the IAV (Berg et al., 2018). The 


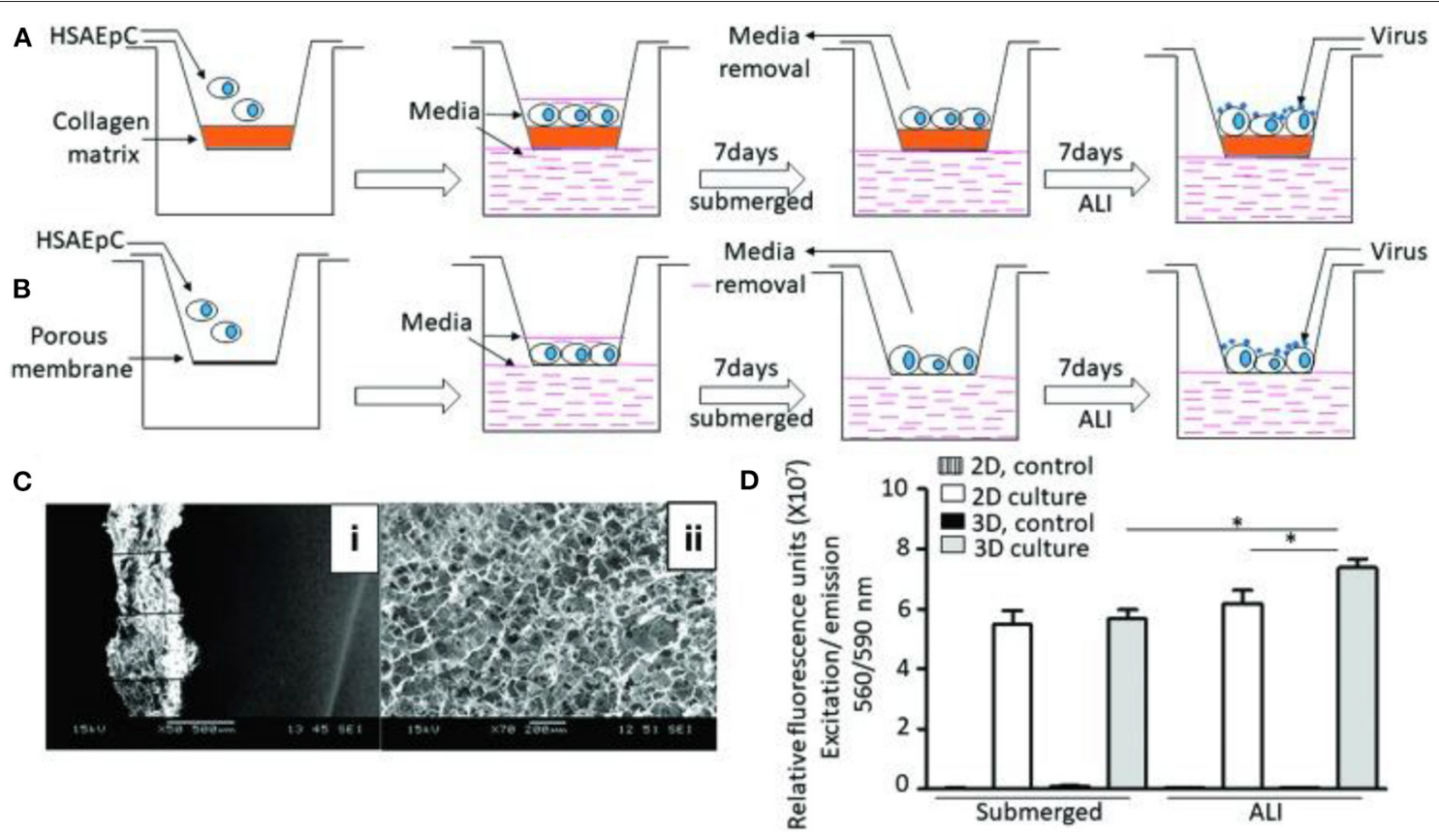

FIGURE 5 | 3D tissue engineering lung model and comparative analysis of 2D and 3D culturing of HSAEpCs (A) 3D culturing of HSAEpCs on chitosan-collagen scaffolds. (B) 2D culturing of HSAEpCs on membrane inserts. (C) SEM images showing the thickness (i) and pores (ii) of the chitosan-collagen scaffolds. (D) Cell viability of HSAEpCs from 2D and 3D culturing. This figure is reprinted under the terms of the Creative Commons Attribution License from Bhowmick et al. (2018). * indicates a significant difference was detected between conditions.

suitability for infection was assessed by infecting the bioink models with the IAV strain $\mathrm{H} 3 \mathrm{~N} 2$, a strain of seasonal influenza. Overall, the study concluded that, although both $2 \mathrm{D}$ and $3 \mathrm{D}$ culture types productively infected the A549 cells, the clustered infection pattern of the $3 \mathrm{D}$ culture more closely resembles the natural biological condition observed in the cells of the human lung than the evenly distributed infection seen in the $2 \mathrm{D}$ culture. Additionally, the 3D printed cells produced an immune response by releasing the antiviral IL-29. Overall, the results of this study can be used to help develop a powerful model that is suitable for studying IAV infections, but may also help study other viruses and the development of new therapies and antiviral strategies.

\section{Using 3D Culture Models to Study the Zika Virus}

Since the effects of SARS-CoV-2 fetal development and the brain are still being researched, the ZIKV study models can be directly translated to study the effects of SARS-CoV-2 infection in the brain, pregnancies, and fetal development. During pregnancy, hormonal levels and immune system function are changed to reduce the potential of fetal rejection, allowing fetal development. This causes higher mortality rates and complications due to viral infection in pregnant women compared to the general population (Alberca et al., 2020). The specific effects of SARS$\mathrm{CoV}-2$ on pregnancies and fetal development are currently largely unknown. It is important to investigate the effects of SARS-CoV-2 on this population as pregnant women are more susceptible to viral infection. Evidence has also shown that SARS$\mathrm{CoV}-2$ can invade cells through the angiotensin-converting enzyme 2 (ACE2) receptor (Baig et al., 2020; Cheng et al., 2020; DosSantos et al., 2020; Hoffmann et al., 2020; Ni et al., 2020). The lungs, kidney, prostate, liver, pancreas, intestines, heart, and brain (predominantly in neurons) all express the ACE2 receptor, which has been thought to contribute to multiple organ system failure with SARS-CoV-2 infection (Ni et al., 2020). With several reports showing that SARS-CoV-2 induces neurological manifestations such as headaches, dizziness, anosmia, and ageusia, as well as more severely stroke, seizure, encephalopathy, and encephalitis (Baig et al., 2020), more research must be conducted to better understand the underlying neurological mechanisms that occur with infection of SARS-CoV-2. Zika virus (ZIKV), a mosquitoborne flavivirus that has been documented to infect humans since 1954. Since a major outbreak in 2007 in the Western Pacific Island of Yap, additional outbreaks have been reported worldwide, with 59 countries and territories having reported ZIKV cases since 2015. Areas worst affected by the virus have warm, humid climates in which the Aedes mosquitos that spread the virus thrive (Agumadu and Ramphul, 2018). The symptoms of the viral infection in humans are often relatively mild such as fever, joint pain, red eyes, headache, and a maculopapular rash usually lasting less than a week with most cases showing no symptoms at all (Musso et al., 2014). Although no mortality has been recorded as a result of ZIKV exposure, infection in pregnant women poses significant developmental risks to the fetus and has been linked to major teratogenic effects such as microcephaly, cerebral calcifications, ventriculomegaly, cerebellar hypoplasia, arthrogryposis, diaphragm paralysis, and visual and hearing impairments (Meneses et al., 2017). The 
A
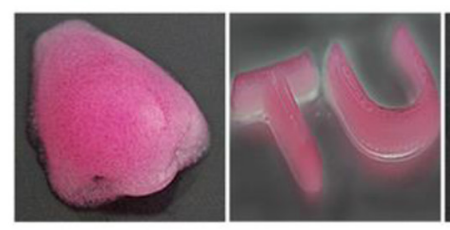

B

hybrid bioink:
C

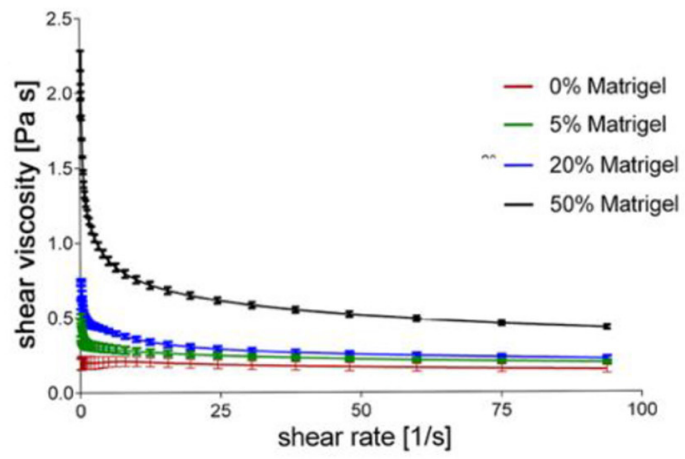

D
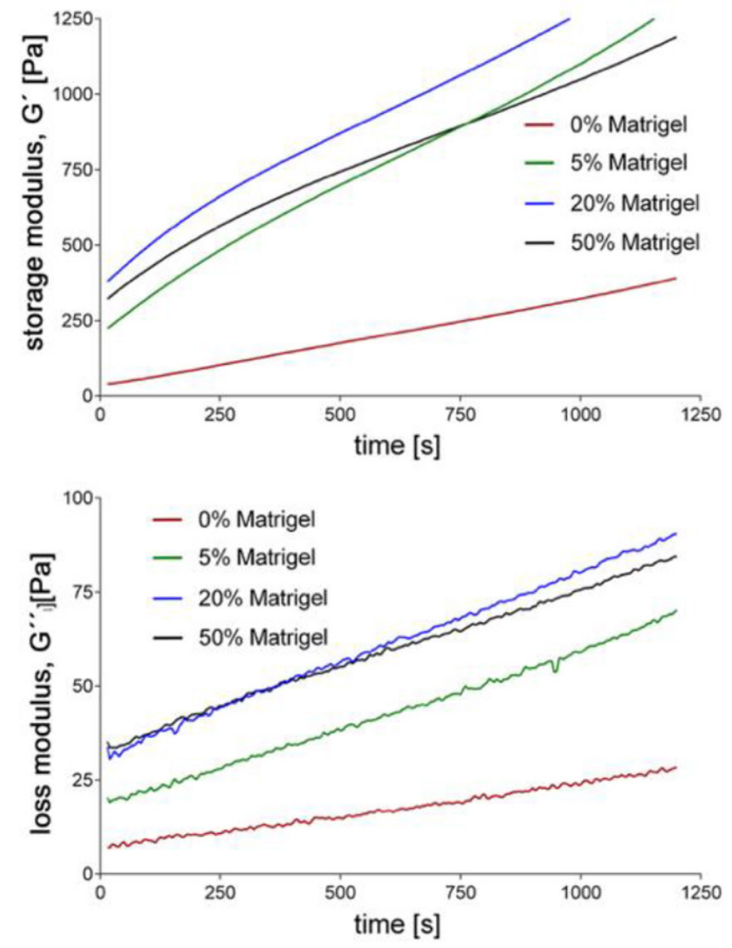

FIGURE 6 | 3D printed cultures of A549 cells. (A) Various shapes of constructs made through extrusion printing. (B) Illustration of 3D printing setup. (C) Viscosity of uncrosslinked bioinks at a shear rate sweep of $1-100 \mathrm{~s}^{-1}$ at $24^{\circ} \mathrm{C}$. (D) Storage and loss modulus of bioink formulas at $1 \mathrm{~Hz}, 24^{\circ} \mathrm{C}$, and $1 \%$ shear strain after the addition of $\mathrm{CaSO}_{4}$. This figure is reprinted under the terms of the Creative Commons Attribution License from Berg et al. (2018).

severity of these conditions has made ZIKV a global focal point in recent years and there is increasing motivation to understand the mechanism through which the ZIKV affects developing brain structures.

In 2016, Tang et al. linked ZIKV exposure to microcephaly by confirming its inhibitory action in the formation and growth of Neuronal Progenitor Cells (NPCs) derived from induced Pluripotent Stem Cells (iPSCs) in 2D cell cultures (Hengli Tang et al., 2016). This landmark study mobilized the world health authorities to recognize the link between brain defects and fetal exposure to ZIKV, and subsequent studies have made use of $2 \mathrm{D}$ cultures for their ease of manipulation and isolation of experimental variables to determine which cells are most susceptible to infection by the virus (Chan et al., 2016). Despite these successes, 2D cell cultures offer little insight into the development of complex structures in the brain due to the fact that the organization of progenitor layers and neuronal layers in the developing cortex cannot be appropriately modeled using 2D monolayer or neurosphere cultures. 3D brain organoids derived from iPSCs are well-suited to this task, and Lancaster et al. (2013) showed they mimic human brain organization, properties and molecular signatures with high fidelity. Dang et al. (2016) were able to demonstrate that developing organoids created using the Lancaster et al. method could be analyzed for their phenotypic and transcriptomic responses to ZIKV exposure, allowing for parallels to be drawn between the stunted growth of the infected organoids and TLR3-mediated dysregulation of neurogenesis and axon guidance. In recent years, techniques for 


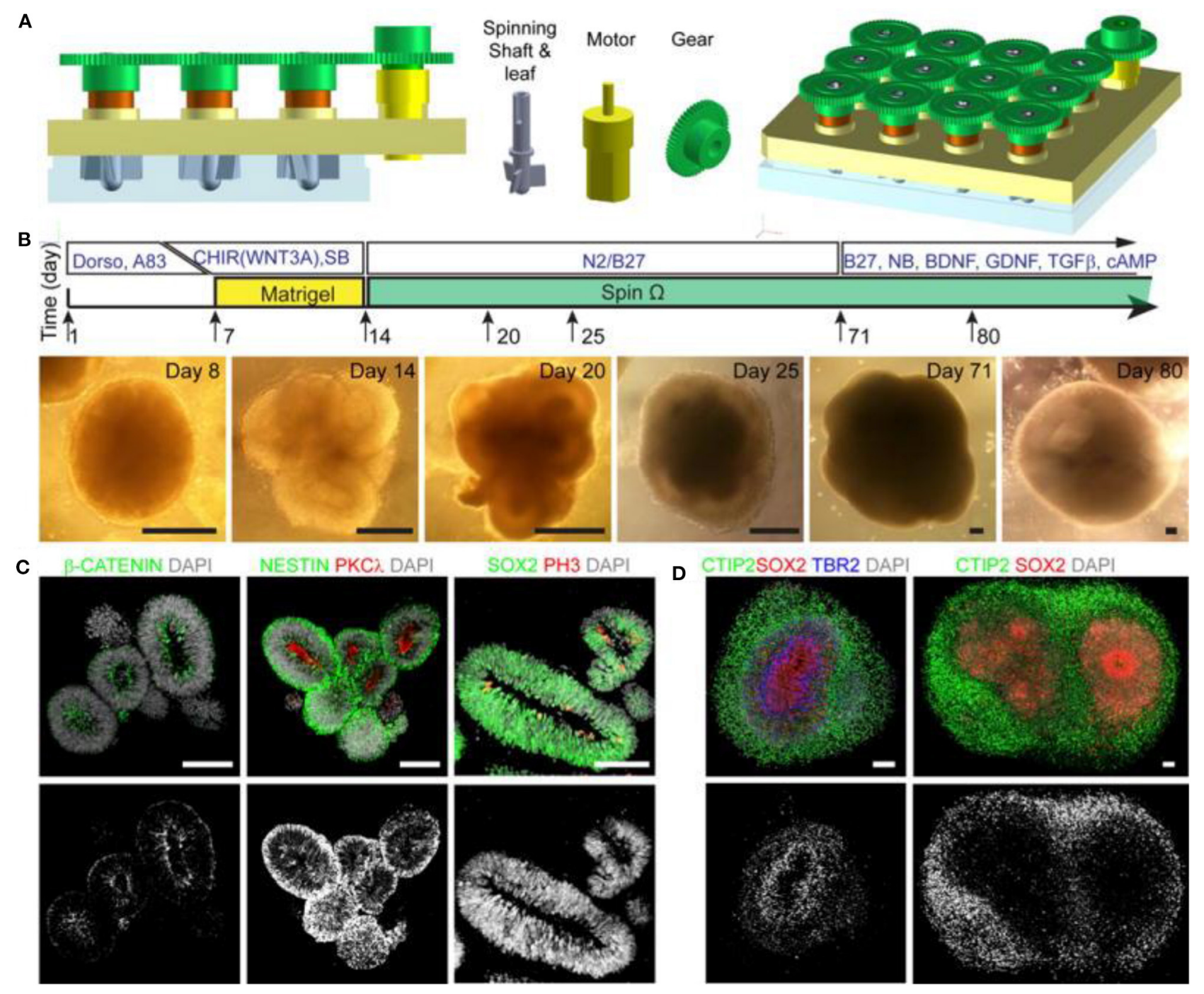

FIGURE 7 | (A) Design of spinning bioreactor used to produce brain organoids. (B) diagram of the organoid protocol and images at the different stages of development (scale bars are $200 \mathrm{~mm}$ ). (C,D) Organoids after immunostaining (scale bars are $100 \mathrm{~mm}$ ). This figure is reprinted under the terms of the Creative Commons Attribution License from Qian et al. (2016).

creating 3D whole brain organoids have greatly improved, with a 2016 study by Qian et al. (2016) notably outlining a novel method involving a $3 \mathrm{D}$ printed spinning bioreactor ("Spin $\Omega$ ") that can produce brain region specific organoids cheaply and in an easily reproduced manner (Figure 7). In the study, cultures were formed from iPSCs treated with dual SMAD inhibitors for 7 days, followed by 7 days embedded in Matrigel after which the organoids were either left in stationary cultures, spun in a $\operatorname{Spin} \Omega$ bioreactor or in an orbital shake bioreactor under similar rotation to the Spin $\Omega$. At day 42, organoids in the stationary culture and in the orbital shaker showed significant neuronal cell death, whereas the spun organoids exhibited increased cell viability. In addition to demonstrating the effectiveness of the spinning reactor method for creating 3D forebrain organoids, the Qian et al. group was able to miniaturize the reactor design allowing for significantly reduced culture medium and incubator space over existing spinning reactor designs. Aside from reducing costs, which allows for scalability and more efficient use of media and growth factors, the design allows for several reactors to be easily set up simultaneously for examining multiple conditions in parallel. The Qian et al. study used these methods to compare the effects of ZIKV exposure at various stages in organoids development to assess the danger at various stages of pregnancy. They found that ZIKV exposure for only 1 day at early stages of organoid development caused many detrimental effects consistent with microcephaly, such as decreased neuronal layer thickness and enlarged lumen/ventricles as well as increased cell death and suppressed proliferation of infected NPCs. The same ZIKV exposure to organoids at day 80 (which are more complex and resemble second trimester fetal development) also 
showed preferential infection of SOX2 NPCs. The results suggest that it is the preferential infection of NPCs by ZIKV that leads to the characteristic features of microcephaly in the developing brain. The study demonstrates the usefulness of 3D organoids, particularly when cultures can be produced large scale under consistent conditions. It also highlights the state of current technology that allows such work to be done at comparatively low cost compared to animal studies.

Although 3D culture techniques have greatly improved when accurately recapitulating in vivo cell-cell and cell-extracellular matrix interactions by more closely approximating living tissue, generation and study of complex and organized structures has remained difficult until recent technological advancements. The most prominent challenges with prior methods involve the death of inner cells in larger organoids due to the lack of vascularization (blood vessel formation) (Zhuang et al., 2018). Spinning bioreactors facilitate better nutrient exchange, which allows for organoids up to a few millimeters in size. Accordingly, Takebe et al. (2013) demonstrated that co-culture with endothelial cells can create vascular-like networks, but more progress is needed for the creation of viable organoids of significant size or complexity. While the issue of vascularization has not yet been solved for creating large brain organoids, methods have been proposed to address this deficiency. Bioinks can be infused with multicellular aggregates called spheroids that are formed either through spontaneous self-arrangement or forced cell adhesion without scaffolds. Spheroids can be adapted to more accurately recapitulate human brain features such a cell diversity, electrical properties and mechanical stiffness (Zhuang et al., 2018). Hsu et al. used spheroids composed of neural and vascular progenitor cells formed by the chitosan (CS)based substrates or other methods. The resulting co-spheroids are suspended in growth factors and an appropriate bioink for both types of progenitor cells and can be printed using available methods (Han and Hsu, 2017). This approach could lead to more accurate and functionally relevant brain organoids and offers a way to study developing neuronal structures for the purposes of therapeutics and understanding disease progression. Recent advances in 3D printing technology have generated significant interest in this topic, which could lead to more accurate viral models.

In other work developing 3D models of brain tissues, Kador et al. developed a technique in 2016 to construct 3D printed scaffolds from electrospun polylactic acid (PLA) nanofibers suspended in hydrogel to guide the formation of retinal ganglion cell structures (Kador et al., 2016). Retinal ganglion cells were 3D printed in an alginate bioink and shown to adhere and organize along the scaffold while maintaining cell viability, neurite outgrowth and their electrophysical properties. A separate study constructed 3D scaffolds from laminin functionalized nanofibers in hyaluronic acid hydrogels and recorded and average increase in length of neurites per cell of $66 \%$ compared to laminin nanofibers on $2 \mathrm{D}$ surfaces and with a $213 \%$ relative increase in proportion of neurite lengths directed along the 3D scaffold compared to the 2D scaffold (Johnson et al., 2014). A remaining challenge with these approaches is that cells seeded onto the scaffolds often grow along the surface resulting in unnatural constraints in morphology that makes the construction of 3D networks difficult. Creation of complex 3D neuronal structures has been aided by the use of sacrificial scaffolds containing guide cavities and micropores that are designed to be dissolved of melted away after the cultures have fully developed (AntillO'Brien et al., 2019). The resulting models have been shown to more closely model human brain tissues and show great promise for the study of brain development and response to viral infection.

Many existing studies focus on clinical outcomes or therapeutics, few consider viral transmission or mobility. 3D bioprinting and organoid cultures have the potential to produce more accurate models of biological interfaces. In the case of ZIKV, the contagion must cross a maternal-fetal interface which is most commonly the blood-placenta barrier or BPB, although intrauterine transmission is also possible, with ZIKV having been detected in the amniotic fluid of effected pregnancies (Costa, 2016). For reasons already mentioned, traditional models typically fail to accurately recapitulate the complex physiology and properties of the BPB. In vivo studies during pregnancy of these tissues are difficult or impossible due to safety and ethical concerns surrounding the mother and fetus, making the availability of accurate and reproducible engineered models a necessity. While many studies exist that demonstrate the effects of ZIKV exposure to both neural and placental cells, in 2018 Arumugasaamy et al. appear to have been the first to use 3D models to study neural cell outcomes following transmission of ZIKV across the BPB (Figures 8A-C) (Arumugasaamy et al., 2018). In this instance, the BPB model was fabricated via casting gelatin methacrylate and crosslinking to form a hydrogel (Figures 8D,E). BeWo B30 cells and human umbilical vein endothelial cells were then seeded on the hydrogel using manual methods (Figure 8F). The resulting model (Figure 8G-K) achieved a glucose transfer rate of $35.9 \%$ compared to a value of 26.5-38.3\% noted in ex vivo perfused placenta (Blundell et al., 2016) which suggests that the model performs comparably to the current "gold standard" within the placental transport field. Additionally, the researchers were able to observe preferential interaction of ZIKV with placental tissue, offering support for prior studies that suggest that the placenta plays a modulating role in transmission (Miner et al., 2016). These findings highlight the potential for better understanding of viral transmission and pathogenesis through biomimetic organoid cultures, and the techniques through which they are created lend themselves well to recent advances in bioprinting technology.

\section{Using 3D Culture Models to Study the Hepatitis Virus}

Hepatitis often refers to an inflamed liver. It can be caused by several factors, most notably, alcohol abuse and Viral Hepatitis. The five types of viral hepatitis are Hepatitis A, B, C, D, and E virus (HAV, HBV, HCV HDV, HEV). The World Health Organization estimates that 325 million people worldwide live with HBV or HCV (Hepatitis, 2020). HAV and HBV currently have effective vaccines while the rest do not. Hepatic models usually utilize one of three categories of cell line each derived 


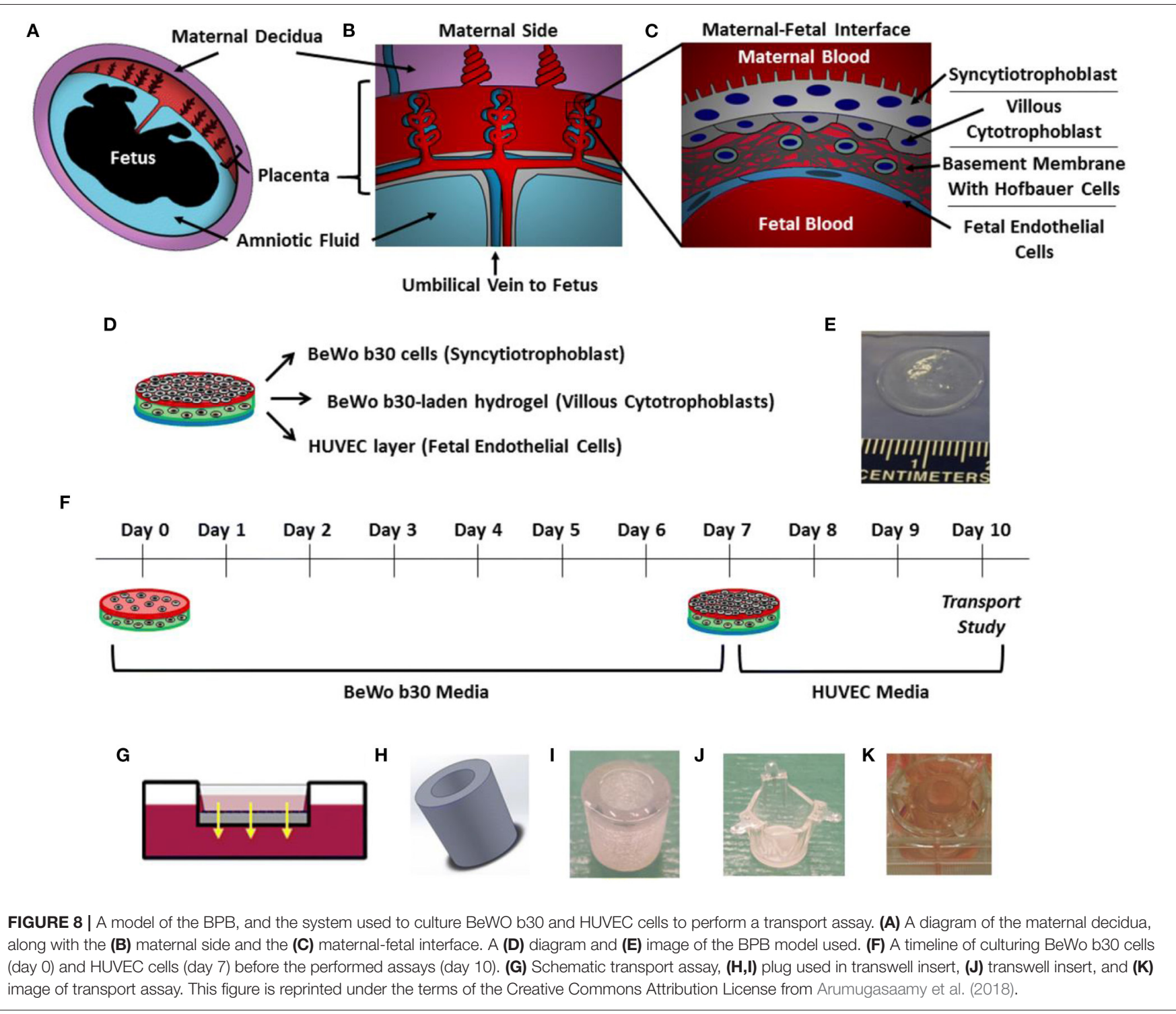

from different sources, including cancer-based cell lines, primary or patient derived cell lines, or stem cell derived models. Cancer derived cell lines are immortalized liver-derived cells that are often utilized for their availability, relative stability, and reproducibility since the cell lines can reproduce indefinitely (Jeon et al., 2017). Common hepatic cancer-based cell lines include HepG2 and Huh7. Hepatocytes in 2D cell cultures do not usually sustain hepatic like functionality over long-term trials in vitro. Nguyen et al. compared patient-derived hepatocytes and non-parenchymal cells in 2D cell culture with a $3 \mathrm{D}$ bioprinted culture it was shown that ATP, albumin, and drug induced enzyme levels decreased after 2 weeks in the $2 \mathrm{D}$ culture while they stayed consistent in the 3D culture over a 4 week period (Nguyen et al., 2016). Histologic analysis of the 3D tissues indicated that the tissues condense and remodel over time, providing stable 3D structures with dense cellularity and no necrosis. The same study showed higher metabolism in the 3D culture evident by CYP3A4 expression from exposure to Rifampicin following day14 of the trial providing further evidence of the advantage of the $3 \mathrm{D}$ culture over 2D. While the study was intended to show the viability of the $3 \mathrm{D}$ culture for drug toxicity testing, the results are promising for testing the ability of viruses to infect liver tissue.

The production of $3 \mathrm{D}$ hepatic structures to more closely mimic in vivo conditions is often sought for potential transplants. Recent advances in 3D bioprinting of liver models showed promising results and possibilities for future viral treatment and testing. A 2018 study by Mazzocchi et al. (2019) used a novel method of forming an extrusion collagen bioink by mixing a ratio of collagen I with hyaluronic acid to print a robust extracellular matrix for liver models. Primary human hepatocytes and liver stellate cells were used to form the hepatic model and testing showed promising cell viability as well as retaining the desired printed shape. The study also tested the tissue model's response to acetaminophen and found appropriately decreased 

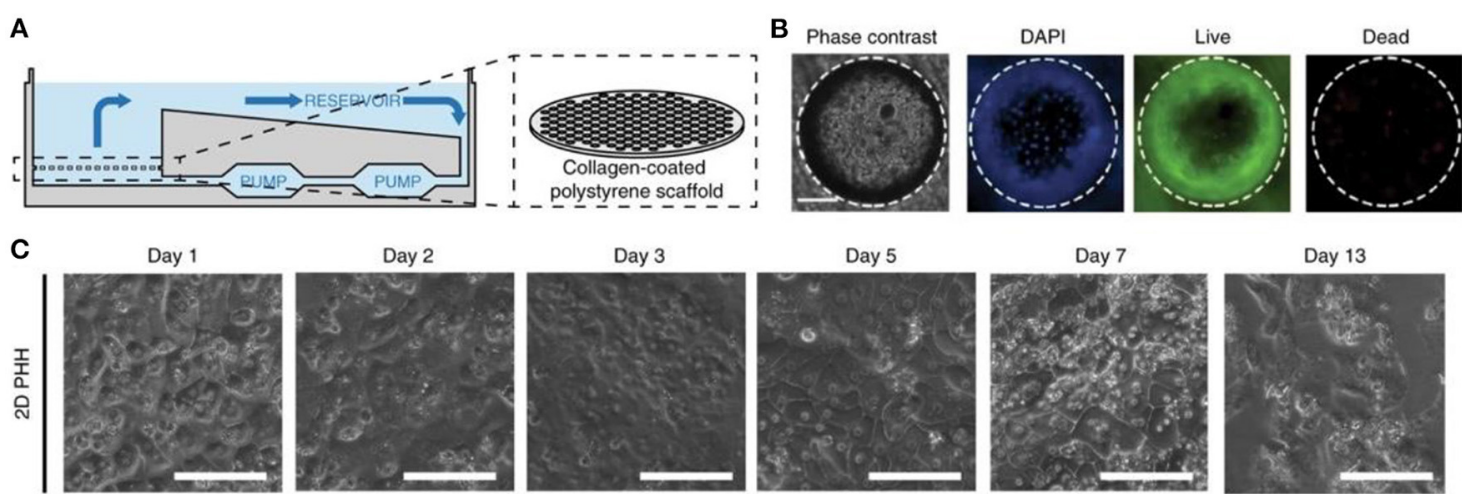

Day 3

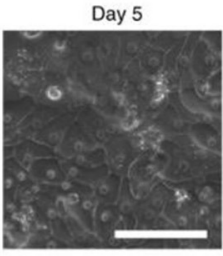

Day 7

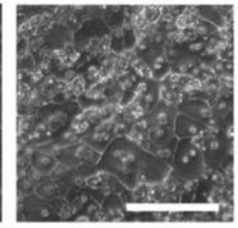

Day 13

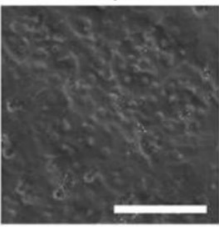

Day 5
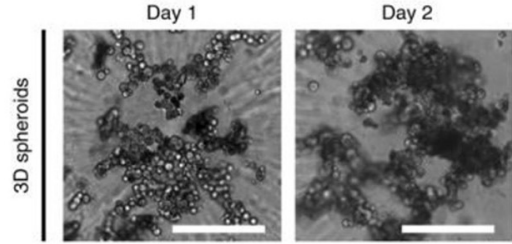

Day 3

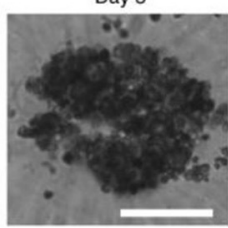

Day 7
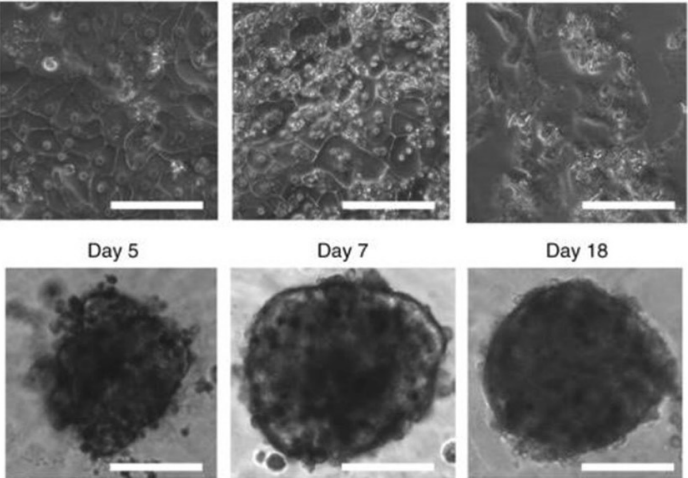

Day 18

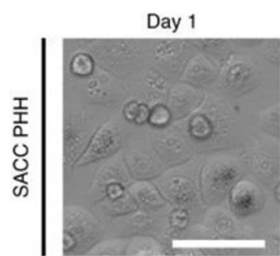

Day 3

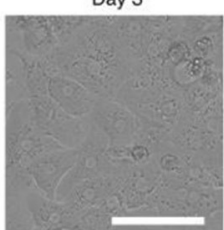

Day 5

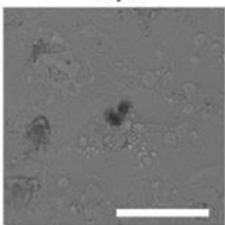

Day 10

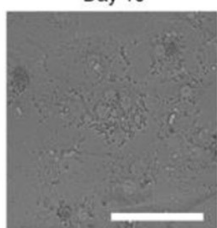

Day 15

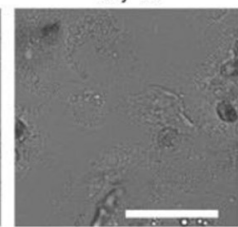

Day 24

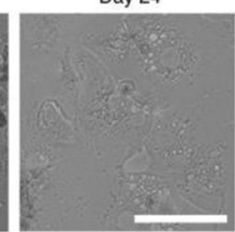

Day

Day 2
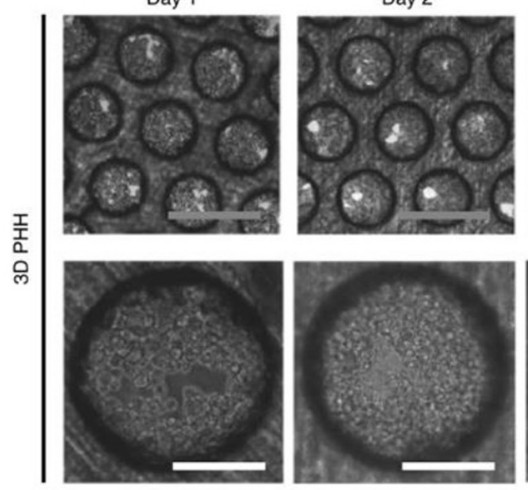

Day 3

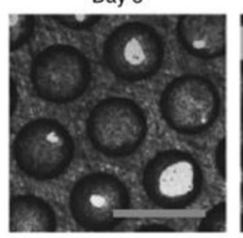

Day 5

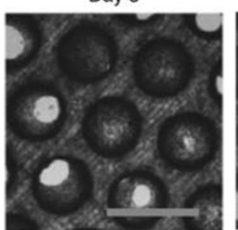

Day 7
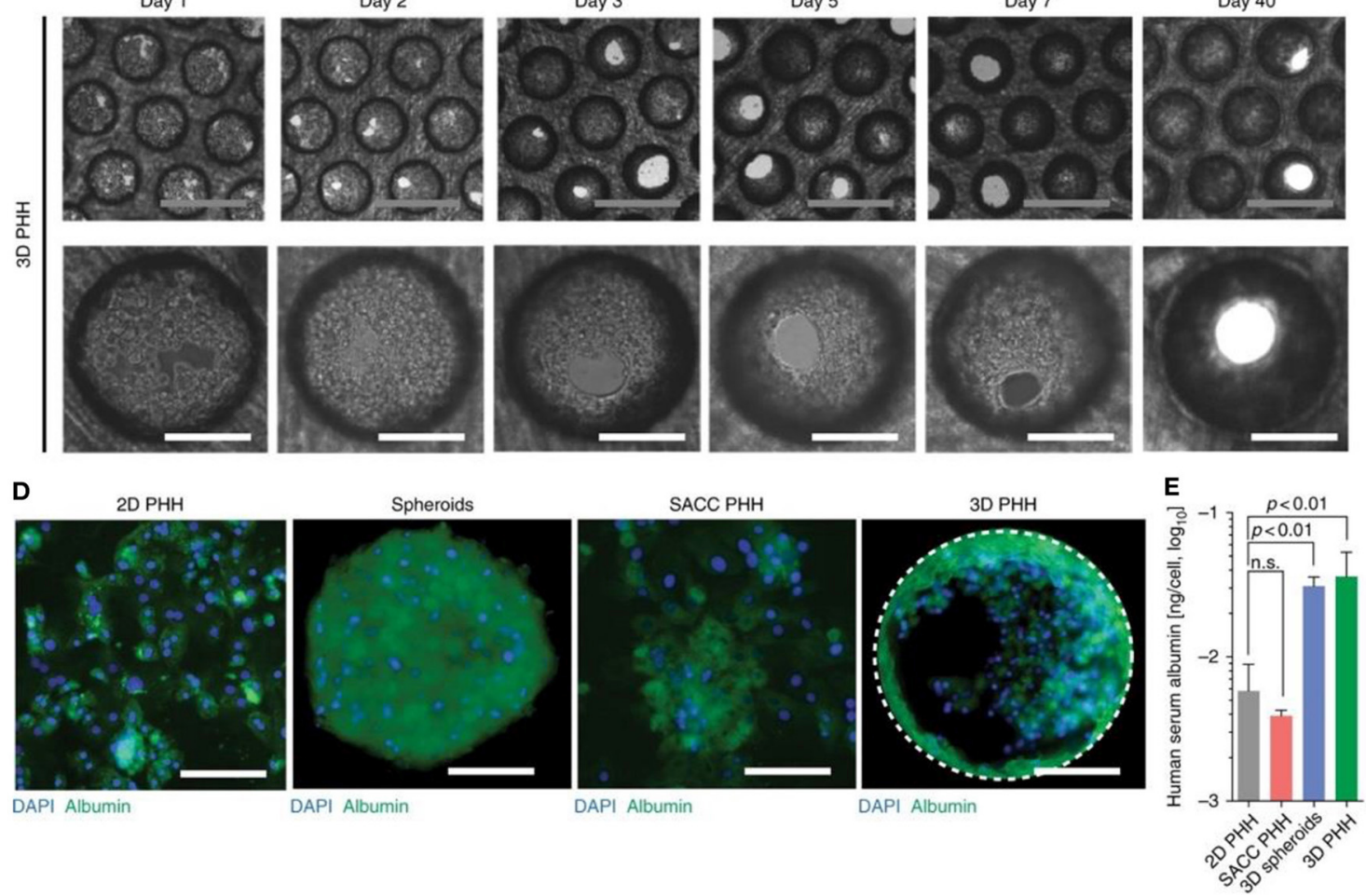

FIGURE 9 | 3D microfluidic system with primary human hepatocytes cultured in a bioreactor. (A) Illustration of the bioreactor showing continuous pumping of media and a collagen-coated scaffold. (B) Cell viability 13 days after seeding 3D cultures. (C) Comparison of the various cell cultures: 2D hepatocytes, 3D spheroids, hepatic and mouse fibroblasts (SACC PHH), and 3D hepatocytes. (D) Immunofluorescence of cell cultures 14 days after seeding. (E) Albumin secretion from cultures 14 days after seeding from ELISA. White scale bars are $200 \mathrm{~mm}$ and gray scale bars are $500 \mathrm{~mm}$. This figure is reprinted under the terms of the Creative Commons Attribution License from Ortega-Prieto et al. (2018). 
levels of albumin and urea secretion responding to toxicity and implying good metabolism properties. Another 2018 study by Hiller et al. (2018) found promising results of infection from an adeno-associated virus vector in a 3D bioprinted liver model using an alginate/gelatin-based bioink to form the extracellular matrix. An issue observed in the past has been the density of hepatic spheroids have prevented adequate virus transduction, this $3 \mathrm{D}$ model would thus improve testing in these cases. The model showed lower levels of albumin and CYP3A4 in the $3 \mathrm{D}$ cultures compared to the monolayer samples. Over a 7 day period, an increase in albumin and CYP3A4 was seen the $3 \mathrm{D}$ model was seen while there was a decrease in the monolayer model. The results of this study showed the 3D model was an adequate hepatic model and demonstrates infection from the test virus. Ortega-Prieto et al. (2018) produced a 3D microfluidic system using primary human hepatocyte cultured in a bioreactor (Figure 9). The culture model described allows for the formation of hepatic microtissues that mimic hepatic sinusoid microarchitecture including tight junctions, functional bile canaliculi, and complete cell polarization. The model showed better albumin and CYP3A4 secretion than 2D monolayers and simple 3D spheroids, and additionally demonstrated an $\mathrm{HBV}$ infection for over 40-days. A similar 2018 study tested a novel method of generating liver organoids using a microwell system with human iPSCs to test HBV infection (Nie et al., 2018). The study compared the differences between liver organoids, which were established through a culture of hiPSC-derived endodermal, mesenchymal, and endothelial cells, with simple hiPSC-derived hepatic-like cells especially with regards to their infection ability. Liver organoids displayed more hepatic like features, such as tight junctions and bile capillaries between hepatic cells. The liver organoids, once infected, showed increased fibrosis and markers believed to play a role in cancer development. Prolonged maintenance in hepatic functionality was also noted in both studies with each mentioning a possible study period of 40days. As well, when infection of HBV was tested, both show increase in HBV covalently closed circular DNA (cccDNA) compared to simpler models. A 2019 study by Zhang et al. utilized decellularized human liver scaffolds engrafted with human hepatocytes cultures to derive a 3D hepatic model for HBV testing (Zhang et al., 2019). The study argues that using primary human hepatocytes $(\mathrm{PHH})$ with decellularized human liver scaffolds mimic in vivo conditions more closely than liver organoid hiPSC and are thus a better candidate for HBV testing. The method showed much higher secretions of albumin and CYP3A4 than 2D models over 14-day periods. The study also noted that the cccDNA of HBV was 30 -folds higher than in $2 \mathrm{D}$ counterparts 7 days after infection. Overall, these models serve as an excellent starting point for modeling the effects of viral infection in the liver.

\section{CONCLUSION}

Modeling biological systems in vitro remains a difficult task, built on reducing complexity so that the effect of various conditions can be observed, while replicating in vivo morphology and biochemistry in a meaningful way. This review illustrates the benefits of using $3 \mathrm{D}$ tissue culture techniques over $2 \mathrm{D}$ tissue culture when studying viral infections and the implications with regards to studying COVID-19. Techniques like spheroid cultures and organoids have been shown to replicate systems of viral infection more accurately than $2 \mathrm{D}$ cultures and to produce morphology and biochemical behaviors required to allow for viral infection in cases where $2 \mathrm{D}$ cultures do not. Bioprinting and OOAC allow for high throughput drug screening and antibody testing on systems that more accurately replicate human tissue than 2D counterparts.

3D culture methods, however, are not without their limitations. The greatest concern with 3D tissue models for the purpose of drug and vaccine development remains to be the ability of the culture model to fully embody the biological, chemical, and physical microenvironmental parameters that mimic in-vivo tissue and disease pathology. Spheroids cultures have been known to exhibit hypoxia and necrosis at their core. The incorporation of spheroids into a microfluidic system that is oxygen and growth factor-permeable can mitigate these limitations (Ryu et al., 2019). The use of an OOAC microfluidic system can mitigate these limitations while also providing a physiologically relevant microenvironment.

Similarly, the incorporation of a rotating or spinning vessel, such as the RWV bioreactor, can help provide the necessary oxygenation and nutrients for development and polarization as described previously. Organoid cultures are typically formed with only the epithelial layer and lack the surrounding tissue microenvironment. Due to this, organoids as well as spheroids lack tissue-tissue interactions, limiting their functionality. This can be addressed by conducting more extensive studies on organoid co-culture systems. Organoid cultures are also commonly dependent on the use of batch-varying xeno-derived ECM or basement membrane, making them that are inapt for human drug studies (Xu et al., 2018). However, there is great potential in the field of personalized medicine for patient-derived organoids to provide robust personalized data, including patientspecific mutation profiles and drug responses (Kim et al., 2020).

Moreover, streamlined processes have not been established for culture methods, which can result in variability within studies especially in regard to high throughput and high content screening. There is also a lack of automated imaging techniques of $3 \mathrm{D}$ cultures that provide satisfactory images. The size of $3 \mathrm{D}$ constructs, material transparency, and depth of microscopes available all limit the ability to achieve clear, representative images (Anton et al., 2015). These techniques must be further developed to continue to advance 3D culturing research. Still, the current progress made on these technologies are especially important during the current SARS-CoV-2 pandemic and will allow us to assess the virus's behavior more accurately in human patients and study treatments and vaccines at a pace never before possible.

\section{AUTHOR CONTRIBUTIONS}

NL, CP, CS, LA, IF, RS, RK, and MH contributed to the writing of the initial draft. IF, LA, EA, and SW edited and formatted the draft for submission. All authors contributed to the article and approved the submitted version. 


\section{FUNDING}

This project funded with support from TechNation wage subsidy program, Coast Capital Savings, Innovate B.C co-op program,
NSERC Discovery Grant program, the Alzheimer's Association, Canada Research Chairs and the Michael Smith Foundation for Health Research and Pacific Parkinson's Research Institute's Innovation to Commercialization grant.

\section{REFERENCES}

Adcock, R. S., Chu, Y. K., Golden, J. E., and Chung, D. H. (2017). Evaluation of anti-Zika virus activities of broad-spectrum antivirals and NIH clinical collection compounds using a cell-based, high-throughput screen assay. Antiviral Res. 138, 47-56. doi: 10.1016/j.antiviral.2016.11.018

Agumadu, V. C., and Ramphul, K. (2018). Zika virus: a review of literature. Cureus. 10:e3025. doi: 10.7759/cureus.3025

Alberca, R. W., Pereira, N. Z., Oliveira, L. M. D. S., Gozzi-Silva, S. C., and Sato, M. N. (2020). Pregnancy, viral infection, and COVID-19. Front. Immunol. 11:1672. doi: 10.3389/fimmu.2020.01672

Andrade, C. F., Wong, A. P., Waddell, T. K., Keshavjee, S., and Liu, M. (2007). Cell-based tissue engineering for lung regeneration. Am. J. Physiol. Lung Cell. Mol. Physiol. 292, 510-518. doi: 10.1152/ajplung.00175.2006

Antill-O'Brien, N., Bourke, J., and O'Connell, C. D. (2019). Layer-by-layer: the case for 3D bioprinting neurons to create patient-specific epilepsy models. Materials 12:3218. doi: 10.3390/ma12193218

Anton, D., Burckel, H., Josset, E., and Noel, G. (2015). Three-dimensional cell culture: a breakthrough in vivo. Int. J. Mol. Sci. 16, 5517-5527. doi: 10.3390/ijms16035517

Arumugasaamy, N., Ettehadieh, L. E., Kuo, C. Y., Paquin-Proulx, D., Kitchen, S. M., Santoro, M., et al. (2018). Biomimetic placenta-fetus model demonstrating maternal-fetal transmission and fetal neural toxicity of Zika virus. Ann. Biomed. Eng. 46, 1963-1974. doi: 10.1007/s10439-018-2090-y

Bahram, M., Mohseni, N., and Moghtader, M. (2016). "Introduction to hydrogels and some recent applications," in In Emerging Concepts in Analysis and Applications of Hydrogels, eds Majee, S. B. (London: InTech).

Baig, A. M., Khaleeq, A., Ali, U., and Syeda, H. (2020). Evidence of the COVID-19 virus targeting the CNS: tissue distribution, host-virus interaction, and proposed neurotropic mechanisms. ACS Chem. Neurosci. 11, 995-998. doi: 10.1021/acschemneuro.0c00122

Berg, J., Hiller, T., Kissner, M. S., Qazi, T. H., Duda, G. N., Hocke, A. C., et al. (2018). Optimization of cell-laden bioinks for 3D bioprinting and efficient infection with influenza A virus. Sci. Rep. 8, 1-13. doi: 10.1038/s41598-018-31880-x

Bhowmick, R., Derakhshan, T., Liang, Y., Ritchey, J., Liu, L., and GappaFahlenkamp, H. (2018). A three-dimensional human tissue-engineered lung model to study influenza a infection. Tissue Eng. Part A 24, 1468-1480. doi: 10.1089/ten.tea.2017.0449

Blundell, C., Tess, E. R., Schanzer, A. S. R., Coutifaris, C., Su, E. J., Parry, S., et al. (2016). A microphysiological model of the human placental barrier. Lab Chip 16, 3065-3073. doi: 10.1039/C6LC00259E

Booth, A. J., Hadley, R., Cornett, A. M., Dreffs, A. A., Matthes, S. A., Tsui, J. L., et al. (2012). Acellular normal and fibrotic human lung matrices as a culture system for in vitro investigation. Am. J. Respir. Crit. Care Med. 186, 866-876. doi: 10.1164/rccm.201204-0754OC

Bouvier, N. M., and Palese, P. (2008). The biology of influenza viruses. Vaccine 26, 49-53. doi: 10.1016/j.vaccine.2008.07.039

Bregu, M., Draper, S. J., Hill, A. V. S., and Greenwood, B. M. (2011). Accelerating vaccine development and deployment: report of a Royal Society satellite meeting. Philos. Trans. R. Soc. B Biol. Sci. 366, 2841-2849. doi: 10.1098/rstb.2011.0100

Breslin, S., and O'Driscoll, L. (2016). The relevance of using 3D cell cultures, in addition to $2 \mathrm{D}$ monolayer cultures, when evaluating breast cancer drug sensitivity and resistance. Oncotarget 7, 45745-45756. doi: 10.18632/oncotarget.9935

Cairns, D. M., Rouleau, N., Parker, R. N., Walsh, K. G., Gehrke, L., and Kaplan, D. L. (2020). A 3D human brain-like tissue model of herpesinduced Alzheimer's disease. Sci. Adv. 6:eaay8828. doi: 10.1126/sciadv.aa y8828
CDC (2021). Summary of Progress since 2009 | Pandemic Influenza (Flu). CDC. Available online at: https://www.cdc.gov/flu/pandemic-resources/h1n1summary.htm (accessed February 14, 2021).

Centeno, E. G. Z., Cimarosti, H., and Bithell, A. (2018). 2D versus 3D human induced pluripotent stem cell-derived cultures for neurodegenerative disease modelling. Mol. Neurodegener. 13:27. doi: 10.1186/s13024-018-0258-4

Chan, J. F. W., Yip, C. C. Y., Tsang, J. O. L., Tee, K. M., Cai, J. P., Chik, K. K. H., et al. (2016). Differential cell line susceptibility to the emerging Zika virus: implications for disease pathogenesis, non-vector-borne human transmission and animal reservoirs. Emerg. Microbes Infect. 5:e93. doi: 10.1038/emi.2016.99

Cheng, Q., Yang, Y., and Gao, J. (2020). Infectivity of human coronavirus in the brain. EBioMedicine 56:102799. doi: 10.1016/j.ebiom.2020.102799

Cortiella, J., Nichols, J. E., Kojima, K., Bonassar, L. J., Dargon, P., Roy, A. K., et al. (2006). Tissue-engineered lung: an in vivo and in vitro comparison of polyglycolic acid and pluronic F-127 hydrogel/somatic lung progenitor cell constructs to support tissue growth. Tissue Eng. 12, 1213-1225. doi: 10.1089/ten.2006.12.1213

Costa, E. C., Moreira, A. F., de Melo-Diogo, D., Gaspar, V. M., Carvalho, M. P., and Correia, I. J. (2016). 3D tumor spheroids: an overview on the tools and techniques used for their analysis. Biotechnol. Adv. 34, 1427-1441. doi: 10.1016/j.biotechadv.2016.11.002

Costa, M. A. (2016). The endocrine function of human placenta: an overview. Reprod. Biomed. Online 32, 14-43. doi: 10.1016/j.rbmo.2015.10.005

D'Aiuto, L., Naciri, J., Radio, N., Tekur, S., Clayton, D., Apodaca, G. et al. (2018). Generation of three-dimensional human neuronal cultures: application to modeling CNS viral infections. Stem Cell Res. Ther. 9:134. doi: 10.1186/s13287-018-0881-6

Dang, J., Tiwari, S. K., Lichinchi, G., Qin, Y., Patil, V. S., Eroshkin, A. M., et al. (2016). Zika virus depletes neural progenitors in human cerebral organoids through activation of the innate immune receptor TLR3. Cell Stem Cell 19, 258-265. doi: 10.1016/j.stem.2016.04.014

de la Vega, L., Lee, C., Sharma, R., Amereh, M., and Willerth, S. M. (2019). 3D bioprinting models of neural tissues: the current state of the field and future directions. Brain Res. Bull. 150, 240-249. doi: 10.1016/j.brainresbull.2019.06.007

DosSantos, M. F., Devalle, S., Aran, V., Capra, D., Roque, N. R., Coelho-Aguiar, J., et al. (2020). Neuromechanisms of SARS-CoV-2: A Review. Front. Neuroanat. 14:37. doi: 10.3389/fnana.2020.00037

Draft Landscape of COVID-19 Candidate Vaccines - 9 June 2020 (2020). World Heatlh Organization.

Draft Landscape and Tracker of COVID-19 Candidate Vaccines. (2021). Available online at: https://www.who.int/publications/m/item/draft-landscape- ofcovid-19-candidate-vaccines (accessed February 15, 2021).

Duval, K., Grover, H., Han, L. H., Mou, Y., Pegoraro, A. F., Fredberg, J., et al. (2017). Modeling physiological events in 2D vs. 3D cell culture. Physiology 32, 266-277. doi: 10.1152/physiol.00036.2016

Gardner, J. K., and Herbst-Kralovetz, M. M. (2016). Three-dimensional rotating wall vessel-derived cell culture models for studying virus-host interactions. Viruses 8:304. doi: 10.3390/v8110304

Gilpin, S. E., and Ott, H. C. (2015). Using nature's platform to engineer bio-artificial lungs. Ann. Am. Thorac. Soc. 12, S45-S49. doi: 10.1513/AnnalsATS.201408-366MG

Goodwin, T. J. (2006). Three-Dimensional Human Bronchial-Tracheal Epithelial Tissue-Like Assemblies (TLAs) as Hosts for Severe Acute Respiratory Syndrome (SARS)-CoV Infection SARS-CoV Infection in a 3-D HBTE Tissue-Like Assembly, NASA Technical Paper.

Gouglas, D., Thanh Le, T., Henderson, K., Kaloudis, A., Danielsen, T., Hammersland, N. C., et al. (2018). Estimating the cost of vaccine development against epidemic infectious diseases: a cost minimisation study. Lancet Glob. Heal. 6, e1386-e1396. doi: 10.1016/S2214-109X(18)30346-2 
Han, H. W., and Hsu, S. H. (2017). Using 3D bioprinting to produce mini-brain. Neural Regen. Res. 12, 1595-1596. doi: 10.4103/1673-5374.217325

He, B., Chen, G., and Zeng, Y. (2016). Three-dimensional cell culture models for investigating human viruses. Virol. Sin. 31, 363-379. doi: 10.1007/s12250-016-3889-z

Hengli Tang, A., Hammack, C., Ogden, S. C., Jin, P., Song, H., and Ming, G. (2016). Zika virus infects human cortical neural progenitors and attenuates their growth. Cell Stem Cell 18, 587-590. doi: 10.1016/j.stem.2016.02.016

Hepatitis. (2020). Available online at: https://www.who.int/health-topics/ hepatitis\#tab=tab_1 (accessed October 4, 2020).

Hiller, T., Berg, J., Elomaa, L., Röhrs, V., Ullah, I., Schaar, K., et al. (2018). Generation of a 3D liver model comprising human extracellular matrix in an alginate/gelatin-based bioink by extrusion bioprinting for infection and transduction studies. Int. J. Mol. Sci. 19:3129. doi: 10.3390/ijms19103129

Hoffmann, M., Kleine-Weber, H., Schroeder, S., Krüger, N., Herrler, T., Erichsen, S., et al. (2020). SARS-CoV-2 cell entry depends on ACE2 and TMPRSS2 and is blocked by a clinically proven protease inhibitor. Cell 181, 271-280.e8. doi: 10.1016/j.cell.2020.02.052

Hu, W.-S. (2020). "Overview of cell culture processes," in Cell Culture Bioprocess Engineering (Boca Raton: CRC Press), 1-35.

Jeon, H., Kang, K., Park, S. A., Kim, W. D., Paik, S. S., Lee, S. H., et al. (2017). Generation of multilayered 3D structures of HepG2 cells using a bio-printing technique. Gut Liver 11, 121-128. doi: 10.5009/gnl16010

Johansen, L. M., DeWald, L. E., Shoemaker, C. J., Hoffstrom, B. G., Lear-Rooney, C. M., Stossel, A., et al. (2015). A screen of approved drugs and molecular probes identifies therapeutics with anti-Ebola virus activity. Sci. Transl. Med. 7:290ra89. doi: 10.1126/scitranslmed.aaa5597

Johnson, C. D., Amato, A. R. D.', and Puhl, D. L. (2014). Patterned and functionalized nanofiber scaffolds in three-dimensional hydrogel constructs enhance neurite outgrowth and directional control. J. Nueral Eng. 11:066009. doi: 10.1088/1741-2560/11/6/066009

Kador, K. E., Grogan, S. P., Dorth,é, E. W., Venugopalan, P., Malek, M. F., Goldberg, J. L., et al. (2016). Control of retinal ganglion cell positioning and neurite growth: combining $3 \mathrm{D}$ printing with radial electrospun scaffolds. Tissue Eng. Part A 22, 286-294. doi: 10.1089/ten.tea.2015.0373

Kapałczyńska, M., Kolenda, T., Przybyła, W., Zajaczkowska, M., Teresiak, A., Filas, V., et al. (2018). 2D and 3D cell cultures - a comparison of different types of cancer cell cultures. Arch. Med. Sci. 14, 910-919. doi: 10.5114/aoms.2016.63743

Kim, J., Koo, B. K., and Knoblich, J. A. (2020). Human organoids: model systems for human biology and medicine. Nat. Rev. Mol. Cell Biol. 21, 571-584. doi: 10.1038/s41580-020-0259-3

Lancaster, M. A., Renner, M., Martin, C. A., Wenzel, D., Bicknell, L. S., Hurles, M. E., et al. (2013). Cerebral organoids model human brain development and microcephaly. Nature 501, 373-379. doi: 10.1038/nature12517

Langhans, S. A. (2018). Three-dimensional in vitro cell culture models in drug discovery and drug repositioning. Front. Pharmacol. 9:6. doi: 10.3389/fphar.2018.00006

Liu, W., He, H., and Zheng, S. Y. (2020). Microfluidics in single-cell virology: technologies and applications. Trends Biotechnol. 38, 1360-1372. doi: 10.1016/j.tibtech.2020.04.010

Lodish, H., Berk, A., Zipursky, S. L., Matsudaira, P., Baltimore, D., and Darnell, J. (2000). Viruses: Structure, Function, and Uses, New York, NY: WH Freeman.

Martin, I., Wendt, D., and Heberer, M. (2004). The role of bioreactors in tissue engineering. Trends Biotechnol. 22, 80-86. doi: 10.1016/j.tibtech.2003.12.001

Mazzocchi, A., Devarasetty, M., Huntwork, R., Soker, S., and Skardal, A. (2019). Optimization of collagen type I-hyaluronan hybrid bioink for 3D bioprinted liver microenvironments. Biofabrication 11:15003. doi: 10.1088/1758-5090/aae543

Meneses, J. D. A., Ishigami, A. C., De Mello, L. M., De Albuquerque, L. L., De Brito, C. A. A., Cordeiro, M. T., et al. (2017). Lessons learned at the epicenter of Brazil's congenital Zika epidemic: evidence from 87 confirmed cases. Clin. Infect. Dis. 64, 1302-1308. doi: 10.1093/cid/cix166

Miller, A. J., and Spence, J. R. (2017). In vitro models to study human lung development, disease and homeostasis. Physiology 32, 246-260. doi: 10.1152/physiol.00041.2016

Miner, J. J., Cao, B., Govero, J., Smith, A. M., Fernandez, E., Cabrera, O. H., et al. (2016). Zika virus infection during pregnancy in mice causes placental damage and fetal demise. Cell 165, 1081-1091. doi: 10.1016/j.cell.2016.05.008
Mondrinos, M. J., Koutzaki, S., Lelkes, P. I., and Finck, C. M. (2007) A tissue-engineered model of fetal distal lung tissue. Am. J. Physiol. Lung Cell. Mol. Physiol. 293, 639-650. doi: 10.1152/ajplung.004 03.2006

Monteil, V., Kwon, H., Prado, P., Hagelkrüys, A., Wimmer, R. A., Stahl, M., et al. (2020). Inhibition of SARS-CoV-2 infections in engineered human tissues using clinical-grade soluble human ACE2. Cell 181, 905-913.e7. doi: 10.1016/j.cell.2020.04.004

Murphy, S. V., and Atala, A. (2014). 3D bioprinting of tissues and organs. Nat. Biotechnol. 32, 773-785. doi: 10.1038/nbt.2958

Musso, D., Nilles, E. J., and Cao-Lormeau, V. M. (2014). Rapid spread of emerging Zika virus in the Pacific area. Clin. Microbiol. Infect. 20, O595-O596. doi: 10.1111/1469-0691.12707

Nguyen, D. G., Funk, J., Robbins, J. B., Crogan-Grundy, C., Presnell, S. C., Singer, T., et al. (2016). Bioprinted 3D primary liver tissues allow assessment of organlevel response to clinical drug induced toxicity in vitro. PLoS ONE 11:e0158674. doi: 10.1371/journal.pone.0158674

Ni, W., Yang, X., Yang, D., Bao, J., Li, R., Xiao, Y., et al. (2020). Role of angiotensin-converting enzyme 2 (ACE2) in COVID-19. Crit. Care 24:422. doi: $10.1186 / \mathrm{s} 13054-020-03120-0$

NIAID (2020). Vaccine Types | NIH: National Institute of Allergy and Infectious Diseases. Available online at: https://www.niaid.nih.gov/research/vaccine-types (accessed August 23, 2020).

Nie, Y. Z., Zheng, Y. W., Miyakawa, K., Murata, S., Zhang, R. R., Sekine, K., et al. (2018). Recapitulation of hepatitis B virus-host interactions in liver organoids from human induced pluripotent stem cells. EBioMedicine 35, 114-123. doi: 10.1016/j.ebiom.2018.08.014

Ortega-Prieto, A. M., Skelton, J. K., Wai, S. N., Large, E., Lussignol, M., Vizcay-Barrena, G., et al. (2018). 3D microfluidic liver cultures as a physiological preclinical tool for hepatitis B virus infection. Nat. Commun. 9:682. doi: 10.1038/s41467-018-02969-8

Ozbolat, I. T. (2015). Bioprinting scale-up tissue and organ constructs for transplantation. Trends Biotechnol. 33, 395-400. doi: 10.1016/j.tibtech.2015.04.005

Peng, W., Datta, P., Ayan, B., Ozbolat, V., Sosnoski, D., and Ozbolat, I. T. (2017). 3D bioprinting for drug discovery and development in pharmaceutics. Acta Biomater. 57, 26-46. doi: 10.1016/j.actbio.2017.05.025

Plunkett, N., and O'Brien, F. J. (2011). Bioreactors in tissue engineering. Technol. Heal. Care 19, 55-69. doi: 10.3233/THC-2011-0605

Qian, X., Nguyen, H. N., Song, M. M., Hadiono, C., Ogden, S. C., Hammack, C., et al. (2016). Brain-region-specific organoids using mini-bioreactors for modeling ZIKV exposure. Cell 165, 1238-1254. doi: 10.1016/j.cell.2016.04.032

Radigan, K. A., Misharin, A. V., Chi, M., and Budinger, G. R. S. (2015). Modeling human influenza infection in the laboratory. Infect. Drug Resist. 8, 311-320. doi: 10.2147/IDR.S58551

Ravi, M., Paramesh, V., Kaviya, S. R., Anuradha, E., and Paul Solomon, F. D. (2015). 3D cell culture systems: advantages and applications. J. Cell. Physiol. 230, 16-26. doi: $10.1002 /$ jcp. 24683

Rock, J. R., Onaitis, M. W., Rawlins, E. L., Lu, Y., Clark, C. P., Xue, Y., et al. (2009). Basal cells as stem cells of the mouse trachea and human airway epithelium. Proc. Natl. Acad. Sci. U. S. A. 106, 12771-12775. doi: 10.1073/pnas.09068 50106

Rosellini, A., Freer, G., Quaranta, P., Dovere, V., Menichini, M., Maggi, F., et al. (2019). Enhanced in vitro virus expression using 3-dimensional cell culture spheroids for infection. J. Virol. Methods 265, 99-104. doi: 10.1016/j.jviromet.2018.12.017

Rossi, G., Manfrin, A., and Lutolf, M. P. (2018). Progress and potential in organoid research. Nat. Rev. Genet. 19, 671-687. doi: 10.1038/s41576-018-0051-9

Ruedinger, F., Lavrentieva, A., Blume, C., Pepelanova, I., and Scheper, T. (2015). Hydrogels for 3D mammalian cell culture: a starting guide for laboratory practice. Appl. Microbiol. Biotechnol. 99, 623-636. doi: 10.1007/s00253-014-6253-y

Ryan, J. A. (2020). Introduction to Animal Cell Culture. Available online at: https:// www.corning.com/catalog/cls/documents/application-notes/CLS-AN-042.pdf (accessed August 20, 2020).

Ryu, N. E., Lee, S. H., and Park, H. (2019). Spheroid culture system methods and applications for mesenchymal stem cells. Cells 8, 1-13. doi: $10.3390 /$ cells 8121620 
Simpson, C., Lee, S. S., Lee, C. S., and Yamauchi, Y. (2018). Microfluidics: an untapped resource in viral diagnostics and viral cell biology. Curr. Clin. Microbiol. Rep. 5, 245-251. doi: 10.1007/s40588-018-0105-y

Singh, K., and Mehta, S. (2016). The clinical development process for a novel preventive vaccine: an overview. J. Postgrad. Med. 62:4. doi: 10.4103/0022-3859.173187

Takayama, K. (2020). Trends in pharmacological sciences in vitro and animal models for SARS-CoV- 2 research trends in pharmacological sciences. Trends Pharmacol. Sci. 41, 513-517. doi: 10.1016/j.tips.2020. 05.005

Takebe, T., Sekine, K., Enomura, M., Koike, H., Kimura, M., Ogaeri, T., et al. (2013). Vascularized and functional human liver from an iPSCderived organ bud transplant. Nature 499, 481-484. doi: 10.1038/nature 12271

Tan, Q., Choi, K. M., Sicard, D., and Tschumperlin, D. J. (2018). Human airway organoid engineering as a step toward lung regeneration and disease modeling. Biomaterials 113, 118-132. doi: 10.1016/j.biomaterials.2016.10.046

Tang, H., Abouleila, Y., Si, L., Ortega-Prieto, A. M., Mummery, C. L., Ingber, D. E., et al. (2020). Human organs-on-chips for virology. Trends Microbiol. 28, 934-946. doi: 10.1016/j.tim.2020.06.005

Tatara, A. M. (2020). Role of tissue engineering in COVID-19 and future viral outbreaks. Tissue Eng. Part A 6, 468-474. doi: 10.1089/ten.tea.2020.0094

Thanh Le, T., Andreadakis, Z., Kumar, A., Gómez Román, R., Tollefsen, S., Saville, M., et al. (2020). The COVID-19 vaccine development landscape. Nat. Rev. Drug Discov. 19, 305-306. doi: 10.1038/d41573-020-00151-8

Thomas, D., Burns, J., Audette, J., and Analysis, A. C. (2016). Clinical Development Success Rates 2006-2015. The Biotechnology Innovation Organization.

Tibbitt, M. W., and Anseth, K. S. (2009). Hydrogels as extracellular matrix mimics for 3D cell culture. Biotechnol. Bioeng. 103, 655-663. doi: 10.1002/bit.22361

Vetter, V., Denizer, G., Friedland, L. R., Krishnan, J., and Shapiro, M. (2018). Understanding modern-day vaccines: what you need to know. Ann. Med. 50, 110-120. doi: 10.1080/07853890.2017.1407035

Wu, Q., Liu, J., Wang, X., Feng, L., Wu, J., Zhu, X., et al. (2020). Organ-on-achip: recent breakthroughs and future prospects. Biomed. Eng. Online 19, 1-19. doi: 10.1186/s12938-020-0752-0
Xu, H., Jiao, Y., Qin, S., Zhao, W., Chu, Q., and Wu, K. (2018). Organoid technology in disease modelling, drug development, personalized treatment and regeneration medicine. Exp. Hematol. Oncol. 7:30. doi: 10.1186/s40164-018-0122-9

Yin, X., Mead, B. E., Safaee, H., Langer, R., Karp, J. M., and Levy, O. (2016). Engineering stem cell organoids. Cell Stem Cell 18, 25-38. doi: 10.1016/j.stem.2015.12.005

Zhang, B., Korolj, A., Lai, B. F. L., and Radisic, M. (2018). Advances in organ-on-achip engineering. Nat. Rev. Mater. 3, 257-278. doi: 10.1038/s41578-018-0034-7

Zhang, Z., Xu, H., Mazza, G., Zhang, M., Frenguelli, L., Liu, Q., et al. (2019). Decellularized human liver scaffold-based three-dimensional culture system facilitate hepatitis B virus infection. J. Biomed. Mater. Res. Part A 107, 1744-1753. doi: 10.1002/jbm.a.36690

Zhu, X., and Ding, X. (2017). Study on a 3D hydrogel-based culture model for characterizing growth of fibroblasts under viral infection and drug treatment. SLAS Discov. 22, 626-634. doi: 10.1177/2472555217701247

Zhuang, P., Sun, A. X., An, J., Chua, C. K., and Chew, S. Y. (2018). 3D neural tissue models: from spheroids to bioprinting. Biomaterials 154, 113-133. doi: 10.1016/j.biomaterials.2017.10.002

Ziegler, C. G. K., Allon, S. J., Nyquist, S. K., Mbano, I. M., Miao, V. N., Tzouanas, C. N., et al. (2020). SARS-CoV-2 receptor ACE2 Is an interferon-stimulated gene in human airway epithelial cells and is detected in specific cell subsets across tissues. Cell 181, 1016-1035.e19. doi: 10.1016/j.cell.2020.04.035

Conflict of Interest: The authors declare that the research was conducted in the absence of any commercial or financial relationships that could be construed as a potential conflict of interest.

Copyright (c) 2021 Lawko, Plaskasovitis, Stokes, Abelseth, Fraser, Sharma, Kirsch, Hasan, Abelseth and Willerth. This is an open-access article distributed under the terms of the Creative Commons Attribution License (CC BY). The use, distribution or reproduction in other forums is permitted, provided the original author(s) and the copyright owner(s) are credited and that the original publication in this journal is cited, in accordance with accepted academic practice. No use, distribution or reproduction is permitted which does not comply with these terms. 